\title{
Cerulean Warbler (Setophaga cerulea) response to operational silviculture in the central Appalachian region
}

\author{
Gretchen E. Nareff ${ }^{\mathrm{a}, *}$, Petra B. Wood ${ }^{\mathrm{b}}$, Donald J. Brown ${ }^{\mathrm{c}, \mathrm{d}}$, Todd Fearer ${ }^{\mathrm{e}}$, Jeffery L. Larkin ${ }^{\mathrm{f}, \mathrm{g}}$, \\ W. Mark Ford ${ }^{\text {h }}$ \\ ${ }^{a}$ West Virginia Cooperative Fish and Wildlife Research Unit, Division of Forestry, West Virginia University, 1145 Evansdale Dr., Morgantown, WV 26506, USA \\ ${ }^{\mathrm{b}}$ U.S. Geological Survey, WV Cooperative Fish and Wildlife Research Unit, Division of Forestry, West Virginia University, 1145 Evansdale Dr., Morgantown, WV 26506 , \\ USA \\ ${ }^{\mathrm{c}}$ Davis College of Agriculture, Natural Resources, and Design, West Virginia University, 1145 Evansdale Dr., Morgantown, WV 26506, USA \\ ${ }^{\mathrm{d}}$ U.S. Forest Service, Northern Research Station, PO Box 404, Parsons, WV 26287, USA \\ e Appalachian Mountains Joint Venture, c/o CMI 1900 Kraft Drive, Suite 105, Blacksburg, VA 24061, USA \\ ${ }^{\mathrm{f}}$ Department of Biology, Weyandt Hall, Indiana University of Pennsylvania, 975 Oakland Ave., Indiana, PA 15705, USA \\ ${ }^{\mathrm{g}}$ American Bird Conservancy, The Plains, VA 20198, USA \\ ${ }^{\mathrm{h}}$ U.S. Geological Survey, Virginia Cooperative Fish and Wildlife Research Unit, Virginia Polytechnic Institute and State University, 106 Cheatham Hall, Blacksburg, VA \\ 24061, USA
}

\section{A R T I C L E I N F O}

\section{Keywords:}

Cerulean Warbler

Silviculture

$N$-mixture

Forest bird management

Upland hardwood forest

\begin{abstract}
A B S T R A C T
The Cerulean Warbler (Setophaga cerulea) is a species of conservation need, with declines linked in part to forest habitat loss on its breeding grounds. Active management of forests benefit the Cerulean Warbler by creating the complex structural conditions preferred by the species, but further research is needed to determine optimal silvicultural strategies. We quantified and compared the broad-scale influence of timber harvests within central Appalachian hardwood forests on estimated abundance and territory density of Cerulean Warblers. We conducted point counts at seven study areas across three states within the central Appalachian region (West Virginia $[n=4]$, Kentucky $[n=1]$, Virginia $[n=2]$ ) and territory mapping at two of the study areas in West Virginia, pre- and post-harvest, for up to five breeding seasons from 2013 to 2017 . Our primary objective was to relate change in abundance to topographic and vegetation metrics to evaluate the effectiveness of current Cerulean Warbler habitat management guidelines. We used single-species hierarchical ( $N$-mixture) models to estimate abundance while accounting for detection biases. Pre-harvest mean basal area among study areas was $29.3 \mathrm{~m}^{2} /$ ha. Harvesting reduced mean basal area among study areas by $40 \%$ (mean $17.2 \mathrm{~m}^{2} / \mathrm{ha}$ ) at harvest interior and harvest edge points. Territory density increased $100 \%(P=0.003)$ from pre-harvest to two years post-harvest. Cerulean Warbler abundance increased with increasing percentage of basal area that comprised tree species preferred for foraging and nesting (i.e., white oak species, sugar maple [Acer saccharum], hickories) or of large diameter trees ( $\geq 40.6 \mathrm{~cm}$ diameter at breast height). Positive population growth was predicted to occur where these vegetation metrics were $>50 \%$ of residual basal area. Post-harvest abundance at harvest interior points was greater than at reference points and when accounting for years-post-harvest in modeling abundance, Cerulean Warbler abundance increased at harvest interior and reference points two years post-harvest and subsequently decreased three years post-harvest. Modeled abundance remained the same at harvest edge points. Increases in abundance and territory density were greater in stands with low pre-harvest densities $(<2$ birds/ point or $<0.40$ territory/ha) of Cerulean Warblers, whereas populations within stands with higher densities preharvest had minimal changes in abundance and territory density. Overall, our results indicate that harvests based on the Cerulean Warbler Management Guidelines for Enhancing Breeding Habitat in Appalachian Hardwood Forests, at all available slope positions and aspects where pre-harvest densities are $<0.40$ territory/ ha, may provide breeding habitat for Cerulean Warblers for at least two years post-harvest in the central Appalachian region.
\end{abstract}

\footnotetext{
* Corresponding author at: 4444 Corona Dr. Suite 215, Corpus Christi, TX 78411, USA.

E-mail addresses: gretchen_nareff@fws.gov (G.E. Nareff), pbwood@wvu.edu (P.B. Wood), donald.brown1@mail.wvu.edu (D.J. Brown), tfearer@abcbirds.org (T. Fearer), larkin@iup.edu (J.L. Larkin), wmford@vt.edu (W.M. Ford).
} 


\section{Introduction}

The Cerulean Warbler (Setophaga cerulea) is a Nearctic-Neotropical migratory songbird with a steeply declining global population (Robbins et al., 1992; Sauer et al., 2017) whose core breeding range is within hardwood forests in the central Appalachian region of the eastern United States. Its decline has been linked to forest habitat loss on the breeding and wintering grounds (Robbins et al., 1992; Hamel et al., 2004) and lack of forest habitat management to provide needed structural complexity within mature forests on the breeding grounds (Boves et al., 2013b). Much of the eastern United States was clearcut in the 19th and early 20th centuries (e.g., Kelty and D'Amato, 2005; Johnson and Govatski, 2013; Thompson et al., 2013). Subsequent regeneration of forests and wildfire suppression following widespread clearcutting produced predominantly even-aged forests, with little heterogeneity in forest structure (Miller et al., 2004) that the birds require during the breeding season (Wood et al., 2013).

Because of its decreasing population size, the Cerulean Warbler is considered a species of conservation need throughout its range. The breeding range extends from its core in the central Appalachian region west to central Minnesota and easternmost Oklahoma and Kansas, east into parts of southern New England and north into southern Quebec and Ontario, Canada (Fig. 1; see Buehler et al., 2013 for detailed range description). The Partners in Flight (PIF) program indicates a $73 \%$ population decline within eastern forests since 1966 when the North American breeding bird surveys began (USGS, 2018); eastern forests contain $72 \%$ of the overall population of Cerulean Warblers (Rosenberg et al., 2016). Further, PIF estimates that it will decrease another $50 \%$ within ca. 25 years if management remains at status quo (Rosenberg et al., 2016). Cerulean Warbler breeding habitat is characterized by large, tall trees within mature deciduous forests (Hamel, 2000). In mountainous terrain, Cerulean Warblers are associated with steep, upper slopes and ridgetops, and north- to northeast-facing slopes (Weakland and Wood, 2005; Hartman et al., 2009). They are also associated with canopy gaps (e.g., through windthrow), internal forest edges (e.g., partially closed-canopy roads), and topography that all provide opportunities for broadcasting their songs to defend territories and attract mates (Weakland and Wood, 2005; Barg et al., 2006; Bakermans and Rodewald, 2009; Wood and Perkins, 2012; Perkins and Wood, 2014).

Silviculture-based forest management can be an important tool to manipulate forest stand structure for gap-dependent mature-forest songbird species like the Cerulean Warbler (Buehler et al., 2008; Boves et al., 2013b; Sheehan et al., 2013; Wood et al., 2013; Hamel et al., 2016). Forest management techniques can be used in mid-seral stands, to mimic, in part, the more complex structural conditions found within late-seral stage forests (e.g., numerous and large canopy gaps, large canopy trees, multiple vegetation strata; Boves et al., 2013b). Canopy gaps allow sunlight to penetrate the overstory, increasing the vigor of desired seed trees, and to reach the forest floor where the sunlight aids in regeneration of multiple strata in the mid- and understories. The regeneration of this vegetation supports invertebrate prey species and thus spatially diverse foraging opportunities for insectivorous birds (Duguay et al., 2001; Newell and Rodewald, 2012), and provides refuge for post-breeding adults and fledglings (Pagen et al., 2000; Vitz and Rodewald, 2006; Porneluzi et al., 2014; Raybuck, 2016; Ruhl et al., 2018). Waiting for natural succession to reach the late-seral stage is not ideal when managing for a species whose population is predicted to decline by another 50\% within ca. 25 years (Rosenberg et al., 2016). Forest management can be used to provide the necessary structural diversity in a short period of time (Boves et al., 2013b; Sheehan et al., 2013).

Previously, a set of experimental forest harvests were used in the central Appalachian region to develop the Cerulean Warbler Management Guidelines for Enhancing Breeding Habitat in Appalachian Hardwood Forests (Wood et al., 2013; hereafter "Guidelines"). Three intensities of harvests were implemented on 10-ha forest stands isolated from other canopy disturbances on the landscape (Boves et al., 2013b). The harvests were within mature, mixed-mesophytic forests, on upper slopes and ridgelines, and on north- to northeast-facing slopes, preferred habitat for the Cerulean Warbler (Weakland and Wood, 2005; Roth and Islam, 2008; Perkins and Wood, 2014). Although the study determined the preferred range of basal area within these conditions $\left(9.2-20.7 \mathrm{~m}^{2} / \mathrm{ha}\right.$; Wood et al., 2013), it is unknown if

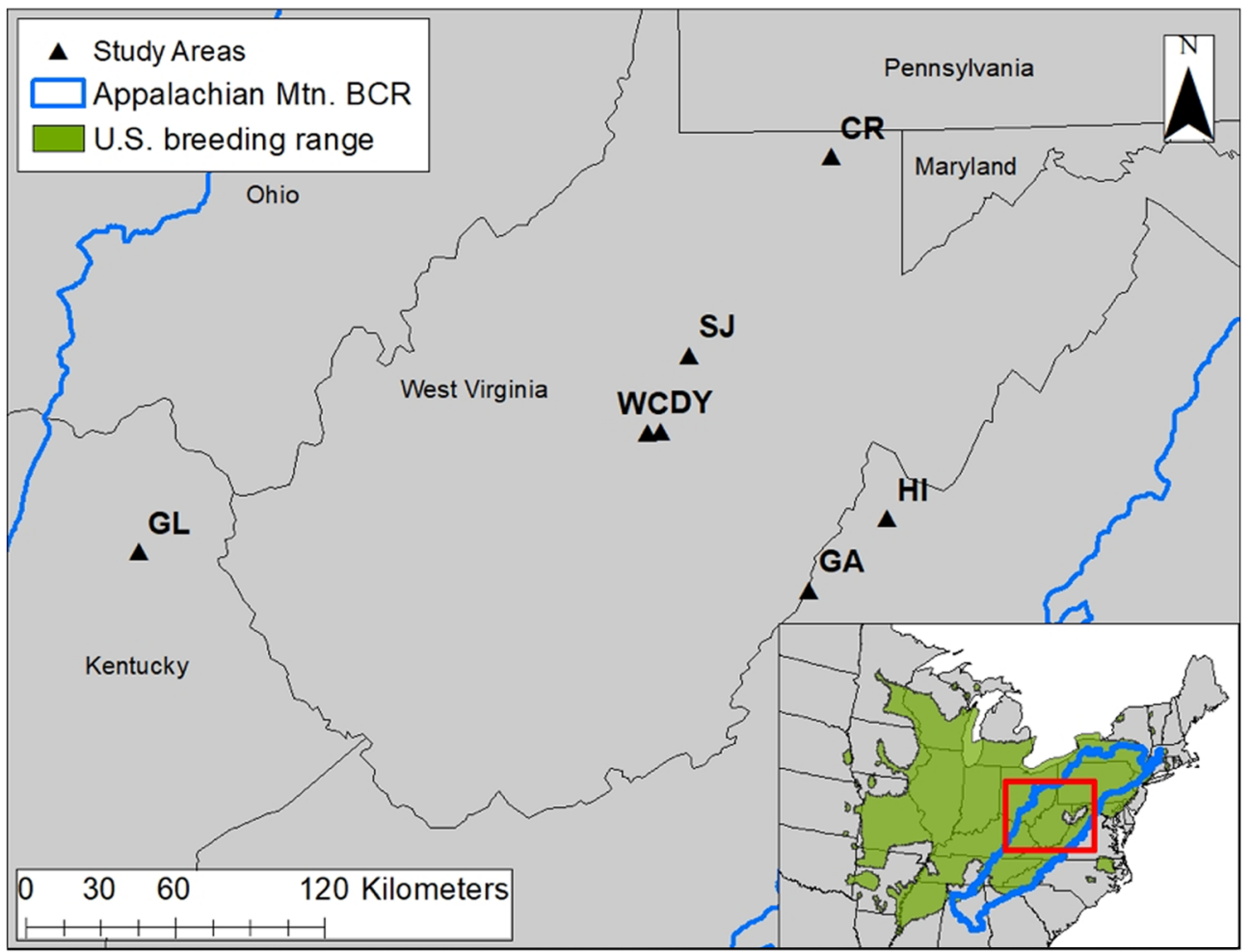

Fig. 1. Location of the regional study areas within the Appalachian Mountains Bird Conservation Region (BCR) for this investigation of Cerulean Warbler (Setophaga cerulea) response to harvests. Study areas are Grayson Lake (GL) Wildlife Management Area (WMA) in Kentucky, Wolf Creek (WC) and Dynamite (DY) at the Elk River WMA, Stonewall Jackson Lake WMA (SJ), and Coopers Rock State Forest (CR) in West Virginia, and Gathright WMA (GA) and Highland WMA (HI) in Virginia. 
Cerulean Warblers would be attracted to similar harvests on less preferred slope positions and aspects. Thus, for our study, harvests were applied to a greater variability of contexts intended to expand upon the Guidelines. Harvests occurred on a broad range of available slope positions (coves to ridgetops) and aspects (Beers aspects 0-2; Beers et al., 1966) rather than being restricted to specific topographic characteristics. Total harvested area at each study area was larger (range 16.4-77.2 ha, mean $40.7 \pm 7.7 \mathrm{ha}$ ) than in the original study, and harvests were not isolated from other disturbances in the landscape. Additionally, two of the study areas were in the Ridge and Valley physiographic region, which was not included in the original study.

Accordingly, our objective was to examine the response of Cerulean Warblers to a range of forest management treatments as part of operational silviculture prescriptions developed by land managers of state agencies, within the varied topographic conditions and forest types in the central Appalachian region. We addressed unanswered questions about the response in abundance and territory density of Cerulean Warblers by evaluating some conditions that are considered less preferred by the species (e.g., southwestern-facing slopes or lower slope positions). We also examined if species composition and size of residual trees within a harvested stand influenced response of Cerulean Warblers. We expected Cerulean Warbler abundance and territory density to increase where basal area was reduced in such a way that would open the canopy, but leave large diameter trees $(\geq 40.6 \mathrm{~cm}$ diameter at breast height [dbh]), especially in stands where residual trees comprised white oaks (Quercus spp.), hickories (Carya spp.), and sugar maple (Acer saccharum). Based on the Guidelines, we expected greater increases to occur where basal area was reduced to $9.2-20.7 \mathrm{~m}^{2} /$ ha on upper portions of north- to northeastern-facing slopes (Wood et al., 2013), but intended to determine if increases occurred where basal area was reduced to similar levels on less preferred slope positions and aspects.

\section{Methods}

\subsection{Regional study area}

We conducted fieldwork during 2013-2016 (Kentucky, West Virginia) and 2013-2017 (Virginia) in contiguous, mature forest landscapes at seven study areas within the central Appalachian region and Appalachian Mountains Bird Conservation Region (NABCI, 2000; Fig. 1). The region is characterized by a series of parallel, southwest- to northeast-trending narrow valleys and high ridges, and dry-mesic and mixed-mesophytic forest types dominated the study areas (USDA Forest Service, 1994). Because all study areas were on Wildlife Management Areas (WMA) or State Forests (SF), they had been managed for a variety of objectives including experimental and teaching harvests, creation of wildlife food plots, or clearings for recreation and skid roads. The study areas (Fig. 1; Table 1) were Grayson Lake WMA, Kentucky (GL); T.M. Gathright WMA, Virginia (GA); Highland WMA, Virginia (HI); Wolf Creek (WC) and Dynamite (DY) within the Elk River WMA, West Virginia; Stonewall Jackson Lake WMA, West Virginia (SJ); and Coopers Rock SF, West Virginia (CR). They fell within three physiographic provinces: GL in the Cumberland Plateau, GA and HI in Ridge and Valley, and all West Virginia study areas in the Allegheny Plateau.

State partners identified areas for management, but all were within the core breeding range of the Cerulean Warbler (Sauer et al., 2017), represented a range of available slope positions, aspects, and elevations, and fell within Cerulean Warbler Focal Areas delineated by the Appalachian Mountains Joint Venture (AMJV) partnership (Fearer, 2011). Focal Areas contain core populations of the Cerulean Warbler that are important for sustaining its current distribution or where additional active forest management will likely enhance the habitat for this bird. Tree species composition differed somewhat among study areas, but common overstory tree species included oaks (northern red oak [Quercus rubra], scarlet oak [Q. coccinea], black oak [Q. velutina], white oak [Q. alba], chestnut oak [Q. montanus]), hickories, red maple (A. rubrum), sugar maple, black cherry (Prunus serotina), and tulip poplar (Liriodendron tulipifera). Elevation at the sampled points ranged from 214 to $1122 \mathrm{~m}$ (mean $586 \mathrm{~m}$ ).

\subsection{Harvests}

The total area harvested at each study area for this project comprised a small proportion of each WMA or state forest (0.4-1.5\%). The total area harvested at each study area (Table 1 ) was $16.4-77.2$ ha (mean $40.7 \pm 7.7 \mathrm{ha}$ ) and comprised small harvest blocks (0.4-6.9 ha), linear harvests (8.8-18.5 ha), or harvest mosaics (Fig. 2) encompassing a diversity of harvest types (i.e., shelterwood, group selection, clearcut with residuals) that resulted in a range of canopy openness. Many of the harvests were described by the local land managers as shelterwood systems, whereby the mature community is removed in two or more successive cuttings separated in time by $5-10$ years, temporarily leaving mature seed trees and resulting in a new even-aged system (Nyland, 2007). However, our study ended before any overstory removal harvests were implemented. The other silvicultural systems used on the study areas included clearcuts with residuals and single-tree to group selection harvests. The ultimate goal of the harvests, outside of the intended use for our study, was to provide conditions where oaks and hickories would make up the bulk of the regenerating class, providing conditions that would allow desired, valuable saplings to outcompete less desirable species (e.g., red maple) (WVDOF, 2006). We did not evaluate Cerulean Warbler response to specific harvest types, but to the resulting conditions in basal area and tree species composition. We designated three point types to make our assessments: harvest interior, harvest edge, and reference (detailed description in Section 2.4.2). We used unharvested areas around, and interspersed with harvests in order to compare Cerulean Warbler abundances between harvested and reference points (Fig. 2). The harvests and surrounding unharvested areas that contained sample points was considered a study area and they ranged $47-224$ ha in size (Table 1 ).

Harvests were applied based on the Guidelines (Wood et al., 2013), but were placed on all available slope positions and aspects by state managers of each study area. Harvests were limited to the dormant season because the entire study region was within the range of the endangered Indiana bat (Myotis sodalis) that relies on trees and snags for day-roosts in the maternity season and therefore summer harvests were precluded (Silvis et al., 2016; Johnson and King, 2018). Our original study design planned for one year of pre-harvest data collection followed by three years of post-harvest data collection at all study areas. However, poor winter weather and logistics related to harvest contracts delayed harvests at all but one of the study areas such that number of years sampled post-harvest varied from 1 to 3 years per study area (Table 1). Consequently, we sampled two additional study areas (DY and CR) that were harvested the winter before initiation of our study to increase post-harvest sample size (hereafter "post-only" study areas) to allow us to examine the influence of years-post-harvest on Cerulean Warbler abundance. Harvests were applied at DY and CR over the winter of 2012-2013 and were initially sampled during the 2013 breeding season (i.e., first year post-harvest). We sampled five study areas both pre- and post-harvest (hereafter "pre-post" study areas). Preharvest data were used for analyses only on the five pre-post study areas. However, post-harvest data from all seven study areas were included in a separate post-only data analysis examining the relationship between Cerulean Warbler abundance to years-post-harvest.

\subsection{Vegetation sampling}

We used standardized protocols across the study areas to quantify canopy tree basal area and tree species composition pre-harvest and the first year post-harvest because these metrics were important characteristics of Cerulean Warbler breeding habitat (Roth and Islam, 2008; 
Table 1

Summary of study areas sampled to evaluate Cerulean Warbler (Setophaga cerulea) response to harvests at seven study areas in the central Appalachian region during 2013-2017. Point count surveys ( $n=5$ study areas) and territory mapping $(n=2$ study areas, SJ and WC) were conducted pre- and post-harvest and point count surveys for three years post-harvest at two additional study areas harvested prior to the initiation of our study. Point counts were surveyed up to 3 years post-harvest.

\begin{tabular}{|c|c|c|c|c|c|c|c|c|}
\hline \multirow[b]{2}{*}{ State } & \multirow[b]{2}{*}{ Study area ${ }^{1}$} & \multicolumn{3}{|c|}{ Point types (\# points sampled) } & \multirow[b]{2}{*}{ Study area size (ha) } & \multirow[b]{2}{*}{ Harvested area (ha) } & \multirow[b]{2}{*}{ Harvest year ${ }^{2}$} & \multirow[b]{2}{*}{ Years-post-harvest ${ }^{3}$} \\
\hline & & Harvest interior & Harvest edge & Reference & & & & \\
\hline \multicolumn{9}{|c|}{ Pre-post study areas } \\
\hline KY & Grayson Lake WMA (GL) & 7 & 7 & 7 & 92 & 16.4 & 2013 & $1-3(n=14)$ \\
\hline VA & Gathright WMA (GA) & 4 & 1 & 6 & 47 & 35.5 & $\begin{array}{l}2014 / \\
2015\end{array}$ & $1-2(n=5)$ \\
\hline VA & Highland WMA (HI) & 9 & 6 & 22 & 224 & 57.1 & $\begin{array}{l}2015 / \\
2016\end{array}$ & $\begin{array}{l}1(\mathrm{n}=15) \\
2(\mathrm{n}=8) \\
3(\mathrm{n}=3)\end{array}$ \\
\hline WV & Stonewall Jackson Lake WMA (SJ) & 4 & 5 & 9 & 92 & 32.0 & $\begin{array}{l}2014 / \\
2015\end{array}$ & $\begin{array}{l}1(n=9) \\
2(n=7)\end{array}$ \\
\hline WV & Wolf Creek (WC) & 4 & 7 & 16 & 111 & 26.6 & $\begin{array}{l}2013 / \\
2014\end{array}$ & $\begin{array}{l}1-2(n=11) \\
3(n=5)\end{array}$ \\
\hline \multicolumn{9}{|c|}{ Post-only study areas } \\
\hline WV & Coopers Rock SF (CR) & 16 & 5 & 18 & 186 & 77.2 & 2012 & $1-3(n=21)$ \\
\hline WV & Dynamite (DY) & 7 & 10 & 17 & 163 & 39.8 & 2012 & $1-3(n=17)$ \\
\hline
\end{tabular}

1 WMA = Wildlife Management Area; SF = State Forest.

2 Harvests occurred during the winter following the breeding season indicated (i.e., a 2013 harvest occurred during winter 2013-2014). At some study areas, harvests were completed over 2 winters.

${ }^{3} \mathrm{n}=$ number of harvested points sampled within each year-post-harvest; all reference points were sampled every year post-harvest.

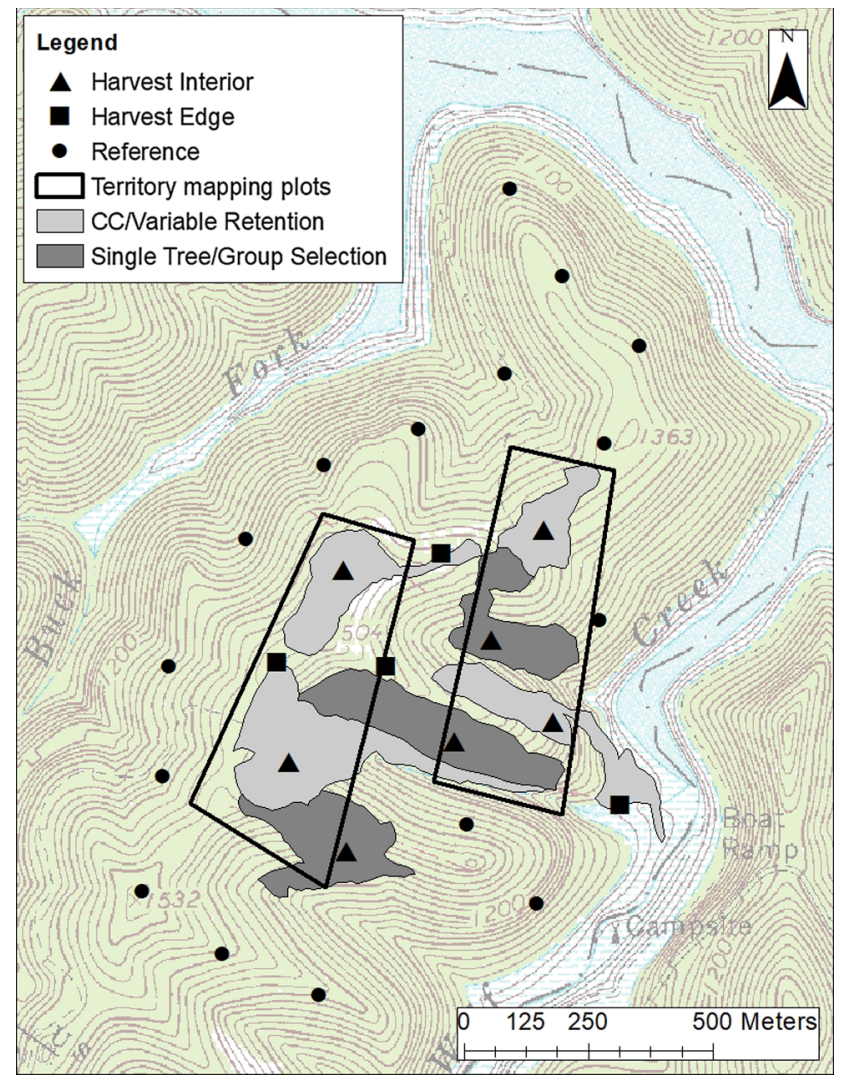

Fig. 2. Wolf Creek harvest within the Elk River Wildlife Management Area in West Virginia shown as an example of our experimental design. Here, harvest interior, harvest edge, and reference point count locations and territory mapping plots were monitored during 2013-2016 for Cerulean Warbler (Setophaga cerulea) abundance and territory density across a timber harvest mosaic. Harvests (clear cut [CC], variable retention, single-tree selection, and group selection) are labeled as described by land managers and were not uniform across each harvest block.
Perkins and Wood, 2014). We placed four plots at each systematically placed point count location; one at the point center, one $35 \mathrm{~m}$ away from the center at magnetic north, and the remaining two at $120^{\circ}$ intervals $35 \mathrm{~m}$ away from the center point (hereafter, "subplots"). We measured post-harvest basal area at 7 points at $\mathrm{HI}$ at only three subplots. We completed variable radius prism plots using a wedge prism (10-factor English or 2.5-factor metric) to tally live trees and snags at every subplot. For each snag, we recorded dbh. For each live tree, we recorded tree species or group (e.g., hickory group, red oak group) and $\mathrm{dbh}$ measured to the nearest centimeter $(\mathrm{cm})$ using a Biltmore stick or $\mathrm{dbh}$ tape. Borderline live trees and snags were counted and included for tree composition values, but every other borderline live tree was removed to calculate total basal area. We sampled harvested subplots once pre-harvest and once post-harvest; we sampled unharvested subplots only once because vegetation did not change.

We calculated mean basal area of stems $\geq 10 \mathrm{~cm}$ dbh per point from the measured subplots at every point within the three point types (Boves et al., 2013b, Sheehan et al., 2013). We also calculated mean basal area of preferred and avoided tree species $\geq 10 \mathrm{~cm} \mathrm{dbh}$ and of all sampled large diameter trees ( $\geq 40.6 \mathrm{~cm} \mathrm{dbh}$; Boves et al., 2013a). Preferred tree species for nesting and foraging included sugar maple, white oaks, and hickories whereas avoided tree species included red maple and red oaks (avoided tree species are used infrequently for foraging or nesting, but they are not uncommon in Cerulean Warbler territories; Barg et al., 2006; George, 2009; Wood and Perkins, 2012; Wood et al., 2013). We then summed the basal areas for each species or group in the subplots and calculated the percentage of basal area of preferred and avoided tree groups and all large diameter trees per point.

\subsection{Avian surveys}

\subsubsection{Territory mapping}

For two of the four West Virginia study areas (SJ and WC), we quantified Cerulean Warbler territory density annually, pre- and postharvest, using territory mapping (Bibby et al., 2000). We centered two 16-17-ha plots over the harvest mosaics at each study area (Fig. 2) for a 
Table 2

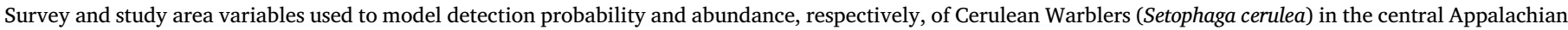
region at seven harvested study areas 2013-2017.

\begin{tabular}{|c|c|c|c|}
\hline Code & Covariate Type & Variable Description & Habitat Component or Use in Models \\
\hline noise & Survey & Noise during visits (levels $0-4$ ) & Detection probability \\
\hline obsv & Survey & 3 observer groups based on experience with bird ID and sampling methods & Detection probability \\
\hline ord & Survey & Ordinal date & Detection probability \\
\hline tssr & Survey & Time-since-sunrise & Detection probability \\
\hline asp & Study area & Beers aspect $(0-2 ; 0$ is xeric and 2 is mesic) & Topography \\
\hline SA & Study area & Study area; 5 pre-post, 2 post-only & Inherent regional differences \\
\hline slope & Study area & Slope position (cove, middle, ridge) & Topography \\
\hline pttype & Study area & Harvest interior, harvest edge, reference & Treatment \\
\hline $\mathrm{ba}^{1}$ & Vegetation & Mean basal area $\left(\mathrm{m}^{2} / \mathrm{ha}\right)$ of tree stems $\geq 10 \mathrm{~cm} \mathrm{dbh}$ & Canopy structure \\
\hline baavoid $^{1}$ & Vegetation & $\%$ basal area $\left(\mathrm{m}^{2} / \mathrm{ha}\right)$ composed of red maple, red oak group & Relationship to avoided tree species \\
\hline balarge $\mathrm{e}^{1}$ & Vegetation & $\%$ basal area $\left(\mathrm{m}^{2} / \mathrm{ha}\right)$ of large diameter trees $(\geq 40.6 \mathrm{~cm} \mathrm{dbh})$ & Relationship to larger trees \\
\hline bapref $^{1}$ & Vegetation & $\%$ of basal area $\left(\mathrm{m}^{2} / \mathrm{ha}\right)$ composed of sugar maple, hickories, white oak group & Relationship to preferred tree species \\
\hline year & Study area & Calendar year (2013-2017) & Inherent annual differences \\
\hline yph & Study area & Years-post-harvest (1-3 years) & Relationship to regeneration \\
\hline
\end{tabular}

1 Linear and quadratic terms were tested for the footnoted variables.

total of four territory mapping plots.

We situated plot boundaries so that each plot would encompass mostly harvested area, although each included a small amount of unharvested area (Fig. 2). We placed plots at least $100 \mathrm{~m}$ apart to avoid counting the same territory on more than one plot. We marked plot boundaries and an internal grid of 50-m intervals with plastic flagging before each field season. Unless a flagged tree was harvested, the flagging remained on the same trees for the duration of the study.

We initiated territory mapping surveys approximately 10 days after Cerulean Warblers first arrived at our study areas in West Virginia (19-23 April) and mapped territories during 7-8 visits per plot through early June 2013-2016. Surveys continued for 6 weeks with a minimum of 4 days between surveys (Bibby et al., 2000). One person surveyed an entire plot within a single morning from dawn to approximately 1100 local time. The same person sampled each plot within a season when logistically possible to maximize detections over repeated visits. We varied the starting points and routes taken through the plots between surveys to reduce time-of-day bias. We recorded singing, calling, and behavioral observations on topographic maps overlaid with the plot grids to accurately note slope position and aspect. We directed special attention to accurately noting multiple individuals that could be heard or seen concurrently (i.e., counter-singing, aggressive interactions) due to its importance in territory delineation. We delineated territory boundaries using detections and instances of counter-singing during the 7-8 visits annually. We estimated territory boundaries in a geographic information system (GIS; ArcMap 10.3, ESRI, 2014). A territory can be delineated from a minimum of 2 territory mapping detections separated by 10 days over 8 territory mapping visits (Bibby et al., 2000; Haché et al., 2013). However, most of the individuals we mapped were reliable in their territorial behavior and once established, they were encountered during $\geq 3$ territory mapping events. We used recurring locations of singing individuals as approximate territory locations, while locations of counter-singing and aggressive interactions likely represented actual territory boundaries.

Using the minimum convex polygon method (Sheehan et al., 2013; Wood and Perkins, 2012), we drew lines in ArcMap to connect the outermost locations of singing males or other territorial cues (i.e., sightings of pairs), using knowledge of the habitat, locations of countersinging males, and nests as guides. We used the connecting lines to form polygons that approximated territory boundaries. Because some territories extended beyond the boundaries of the territory mapping plots, we included in analyses territories with $\geq 50 \%$ of their area within the territory mapping plot (Sheehan et al., 2013). We calculated annual territory density (\# territory/ha) of individual territory mapping plots by summing the number of territories within a plot and dividing by the total area of the territory mapping plot.

\subsubsection{Point counts}

We systematically placed point count locations (points) throughout the harvest and reference stands, spacing points $\geq 200 \mathrm{~m}$ from each other to avoid double counting birds. We placed harvest interior points within harvest units and $\geq 50 \mathrm{~m}$ from the closest edge of a harvest (mean distance $64.7 \pm 4.5 \mathrm{~m}$ ); harvest edge points could be inside or outside the harvest boundaries but all were $<50 \mathrm{~m}$ from the closest edge of a harvest (mean distance $5.8 \pm 1.9 \mathrm{~m}$ ); and reference points were $\geq 50 \mathrm{~m}$, but generally $\geq 100 \mathrm{~m}$ from harvests (mean $319.8 \pm 28.5 \mathrm{~m} ; 84 \%$ of points $\geq 100 \mathrm{~m}$ ). Edge effects for avian species are generally considered to occur within $50 \mathrm{~m}$ of forest edge (Paton, 1994). We placed reference points in areas that were similar to preharvest conditions at the harvested points and where no harvests would take place for the duration of the project. Thus, reference points represented mature forest conditions generally available in our study landscape, and as such did not occur in mature forest conditions without internal edges (e.g., hiking trails, campgrounds, skid roads, water features).

We surveyed for Cerulean Warbler abundance at a total of 187 points including 114 pre-post points (28 harvest interior, 26 harvest edge, and 60 reference) and 73 post-only points ( 27 harvest interior, 11 harvest edge, and 35 reference). All points were sampled 2013-2016 except the post-only sites (CR and DY), which we dropped in 2016 because we had acquired data for 1-3 years post-harvest. In 2017, we sampled only the VA study areas (GA and HI; Table 1) to acquire the one-year post-harvest data for these study areas. We surveyed from 15 May to 29 June each year, which coincides with the peak breeding season for songbirds in the central Appalachian region (e.g., Newell and Rodewald, 2012; Wood and Perkins, 2012; Boves et al., 2013a; Sauer et al., 2017). Surveys were conducted on days without steady rain or sustained winds $>19$ kilometers per hour (i.e., $>3$ on the Beaufort scale), between sunrise and $1100 \mathrm{~h}$. We recorded noise level, cloud cover, wind, and start time for each survey to incorporate into detection models (Table 2).

At each study area, a field crew of point count surveyors or local biologists conducted the avian sampling. Most surveyors were experienced prior to the initiation of the study, but all were trained in bird identification, distance estimation, and sampling protocols before surveys began. We surveyed each point three times each year, with approximately one week between visits when possible. We attempted to survey points in a different order each visit to reduce time-of-day bias and by a different observer to reduce observer bias. We recorded detections within five distance bands indicating the distance of the bird from the observer $(0-25 \mathrm{~m},>25-50 \mathrm{~m},>50-75 \mathrm{~m},>75-100 \mathrm{~m}$, and $>100 \mathrm{~m}$ ) but used only the first two distance bands in analyses (Section 2.5.2). 


\subsubsection{Topographic metrics}

We used a 1:24,000 digital elevation model (DEM; USGS, 2017) to calculate two topographic metrics (slope position and Beers aspect) within the 50-m radius for each point using the "Topography Tools for ArcGIS 10.3 and earlier" toolbox (version 10.3, Dilts, 2015). We classified each point with one of six categories of slope position by obtaining the majority from the raster layer in GIS, using the "zonal statistic as table" tool, within the $50-\mathrm{m}$ point count radius. Three categories were represented as the majority at our sample points: cove, middle, and ridge (Table 2). Beers aspect (0-2; Beers et al., 1966) represents forest productivity with the least productive, xeric aspects approaching 0 and the most productive, mesic aspects having values approaching 2. We assigned the mean Beers aspect within the 50-m point count radius for each point from the raster layer in GIS using the "zonal statistic as table" tool.

\subsection{Statistical analyses}

\subsubsection{Territory density}

We used one-way repeated measures analysis of variance (ANOVA) and Tukey's honestly significant difference (HSD) post hoc test to test for differences in our response variable, territory density, among levels of our predictor variable, years-post-harvest, with territory mapping plots as a random effect. We assigned the calculated territory densities to preharvest, one-year post-harvest, and two-years post-harvest. We tested the normal distribution and sphericity assumptions of ANOVA with a Shapiro Wilks test and Mauchly's test, respectively. We considered results significant at $\alpha=0.05$.

\subsubsection{Point counts}

We included bird detections within $50 \mathrm{~m}$ of the point count (point) center in our analyses to more closely relate abundance to vegetation and topographic characteristics measured within 50-m radius of each point. Cerulean Warblers have small territories (usually $<1.0$ ha; Oliarnyk and Robertson, 1996; Robbins et al., 2009; Kaminski and Islam, 2013). Thus, any bird detected beyond $50 \mathrm{~m}$ of the point center will likely have little to no relationship with the vegetation and topographic characteristics at that point (Hutto, 2016).

We used an $\mathrm{N}$-mixture modeling approach to estimate abundance for the pre-post and post-only datasets separately. $\mathrm{N}$-mixture models use spatially and temporally repeated counts to estimate abundance as a product of ecological processes and imperfect detection by linking two sub-models (Royle, 2004; Dail and Madsen, 2011; Kéry, 2018). This is important because birds are likely not distributed randomly in space, as the landscape is heterogeneous, providing some patches of habitat suitable for breeding within an unsuitable matrix. Habitat and topographic covariates can be used to explain this distribution explicitly in the abundance estimation sub-model (Royle, 2004), whereas surveyspecific covariates (e.g., observer, weather) can be used to explain detection probability (Table 2). Using this approach, average abundance across points that share a spatial attribute (e.g., all harvest interior points, all points on ridges) can be estimated, as can temporal changes in abundance using dynamic models (Dail and Madsen, 2011; Bellier et al., 2016).

$\mathrm{N}$-mixture models are valuable to ecology, conservation, and monitoring wildlife populations because they provide an analysis method that is more efficient, less expensive, and can be applied to more easily attainable data, over a larger spatiotemporal extent than true markrecapture studies (Kéry, 2018). Use of $N$-mixture models to analyze count data (e.g., Barker et al., 2018) has been criticized because detection probability is assumed constant for all visits and auxiliary data are not used to estimate detection probability. However, $\mathrm{N}$-mixture modeling is also considered a significant advancement in abundance modeling and some of the doubts projected on this method have been tested and determined unfounded (Joseph et al., 2009; Kéry, 2018).

\subsubsection{Hierarchical model configuration}

We used package unmarked (version 0.11-0, Fiske and Chandler, 2011) in program $\mathrm{R}$ (version 3.5.0, R Core Team, 2018) for all hierarchical modeling. We specified the open population model for pre-post data (Section 2.5.5) using the function "pcountOpen" with dynamics $=$ trend, and the closed population model for post-only data (Section 2.5.6.) using the function "pcount". For both datasets, we used Poisson distribution and Akaike's Information Criterion corrected for small sample size bias (AICc, Burnham and Anderson, 2002). Model convergence was verified through sensitivity analysis by increasing $\mathrm{K}$ (the upper summation limit for the summation over the random effects in the integrated likelihood) and confirming no change in beta estimates (Kéry and Royle, 2016).

\subsubsection{Detection probability covariates}

We used model selection to determine important detection probability covariates for inclusion in final analyses (Fuller et al., 2016). All candidate models included a covariate for observer proficiency, which was based on an observer's previous experience as evaluated by team leaders in each state. The 36 observers were ranked as either low, moderate, or high proficiency, relative to all other observers that sampled birds during the study. We tested all combinations of observer with time-since-sunrise, ordinal date, and noise. Using AICc (Burnham and Anderson, 2002), we selected the top pre-post-harvest and postharvest-only detection probability models and used them for all subsequent analyses.

\subsubsection{Pre-post-harvest analyses}

We used open population $N$-mixture models to estimate abundance, population growth rate, changes in Cerulean Warbler abundance from pre- to post-harvest, and to quantify the influence of environmental variables on those parameters (Dail and Madsen, 2011). Because preharvest abundance influences post-harvest abundance of songbirds (e.g., Wood et al., 2013; Porneluzi et al., 2014), inferences based on open population $\mathrm{N}$-mixture models, which account for pre-harvest abundance, should be more robust than models that only examine postharvest abundance patterns. Open population $N$-mixture models relax the closure assumption between primary sampling periods, allowing for estimation of population changes between breeding seasons for migratory songbirds. Closure is assumed among secondary sampling periods within a season (i.e., across the three visits). This is a reasonable assumption with songbirds during the breeding season when pairs have an established territory (Royle, 2004), and when multiple visits are conducted within a short amount of time (here, 6 weeks).

For this analysis, we used the simplest open population dynamics structure:

$\mathrm{N}(i, t)=\mathrm{N}\left(i_{i, t-1}\right) \times \Omega$

where estimated abundance $(\mathrm{N})$ at time $t$ is based on $\mathrm{N}$ at time $t-1$ and the estimated population growth rate $(\Omega)$. This model does not separately estimate apparent survival and recruitment. We modeled point count data from the year immediately pre-harvest and the first year post-harvest for pre-post analyses (Nareff et al., 2019 dataset 1) to compare abundance immediately before and after harvesting.

We included study area as a covariate for initial abundance in every pre-post model to account for inherent differences in Cerulean Warbler abundance among study areas. To delineate important predictors of population growth rate, we tested vegetation and topographic variables that are relevant to Cerulean Warbler occurrence and abundance based on previous studies (Table 2; Boves et al., 2013b, Sheehan et al., 2013; Wood et al., 2013). We first used the 114 pre-post points to examine the influence of study area-level variables (i.e., slope position, Beers aspect, and point type) on abundance (Table 3 ). We developed three models to determine if slope position and aspect influence the Cerulean Warbler response to point type. To estimate changes between pre- and postharvest abundance, we used the "ranef" unmarked function. This 
Table 3

Model selection process to determine the most parsimonious $\mathrm{N}$-mixture models that explain change in Cerulean Warbler (Setophaga cerulea) abundance from pre- to post-harvest at five study areas in Kentucky, Virginia, and West Virginia 2013-2017. $N$-mixture models for 114 sample points with one year pre-harvest and one year post-harvest data are shown. Models are presented in order of AICc value with the top model (i.e., lowest AICc value) first. $\mathrm{K}$ is the number of parameters in a model, AICc is the Akaike's Information Criterion value for small sample sizes, which measures the fit of a model relative to other models, $\triangle \mathrm{AICc}$ is the difference between each model's AICc value and the lowest AICc value in the candidate set, and $\mathrm{w}_{\mathrm{i}}$ is the Akaike weight of each model in relation to the entire candidate set. Codes for variables are defined in Table 2.

\begin{tabular}{|c|c|c|c|c|}
\hline Model $^{1}$ & $\mathrm{~K}$ & AICc & $\triangle \mathrm{AICc}$ & $\mathrm{w}_{\mathrm{i}}$ \\
\hline \multicolumn{5}{|l|}{ Model set 1: point type and topographic variables } \\
\hline$\lambda$ (SA) $\Omega$ (pttype) p (obsv + ord + noise + tssr) & 14 & 770.77 & 0.00 & 0.69 \\
\hline $\begin{array}{l}\lambda(\text { SA) } \Omega \text { (pttype }+ \text { asp) } p \\
\quad(\text { obsv }+ \text { ord }+ \text { noise }+ \text { tssr })\end{array}$ & 15 & 773.39 & 2.62 & 0.19 \\
\hline $\begin{array}{l}\lambda(\text { SA) } \Omega \text { (pttype }+ \text { slope }) \mathrm{p} \\
\quad(\text { obsv }+ \text { ord }+ \text { noise }+ \text { tssr })\end{array}$ & 16 & 774.17 & 3.40 & 0.12 \\
\hline \multicolumn{5}{|l|}{ Model set 2: vegetation variables } \\
\hline$\lambda$ (SA) $\Omega$ (bapref) p (obsv + ord + noise + tssr $)$ & 13 & 767.25 & 0.00 & 0.39 \\
\hline$\lambda$ (SA) $\Omega$ (balarge) p (obsv + ord + noise + tssr $)$ & 13 & 768.61 & 1.36 & 0.20 \\
\hline$\lambda$ (SA) $\Omega$ (baavoid^2) p (obsv + ord + noise + tssr) & 14 & 769.58 & 2.33 & 0.12 \\
\hline$\lambda(\mathrm{SA}) \Omega\left(\right.$ bapref $^{ } 2$ ) $\mathrm{p}$ (obsv + ord + noise + tssr $)$ & 14 & 769.62 & 2.37 & 0.12 \\
\hline$\lambda$ (SA) $\Omega$ (balarge 2 ) p (obsv + ord + noise + tssr $)$ & 14 & 771.21 & 3.95 & 0.05 \\
\hline$\lambda$ (SA) $\Omega$ (ba) p (obsv + ord + noise + tssr) & 13 & 771.40 & 4.14 & 0.05 \\
\hline$\lambda$ (SA) $\Omega$ (baavoid) p (obsv + ord + noise + tssr) & 13 & 771.44 & 4.19 & 0.05 \\
\hline$\lambda(\mathrm{SA}) \Omega\left(\mathrm{ba}^{\wedge} 2\right) \mathrm{p}(\mathrm{obsv}+$ ord + noise + tssr $)$ & 14 & 773.29 & 6.04 & 0.02 \\
\hline
\end{tabular}

${ }^{1} \lambda=$ initial abundance, $\Omega=$ population growth rate, $\mathrm{p}=$ detection probability.

function estimates conditional abundance at each sample point, based on count data, covariates, and estimated detection probability. In a second model set, we examined the influence of basal area (Table 3), because basal area within and across point types was highly variable. Vegetation metrics from each harvest interior, harvest edge, and reference point included mean basal area of stems $\geq 10 \mathrm{~cm} \mathrm{dbh}$, percent mean basal area of preferred and avoided tree species $(\geq 10 \mathrm{~cm} \mathrm{dbh})$, percent mean basal area of all large diameter trees $(\geq 40.6 \mathrm{~cm} \mathrm{dbh})$, and the quadratic terms for these four basal area measurements (Table 3). For each model selection analysis, we used AICc to determine the most parsimonious model. Finally, we used the selected models to predict Cerulean Warbler abundance and population growth over a range of values for the most supported vegetation variables. We again used the "ranef" function as previously described and we also used the "predict" function to estimate abundance within a specified range of environmental variables (e.g., abundance at points with basal area between 5 and $50 \mathrm{~m}^{2} / \mathrm{ha}$ ), based on our model input.

\subsubsection{Post-harvest-only analyses}

We developed four models using the point type and years-postharvest variables to estimate the influence of years-post-harvest on Cerulean Warbler abundance (Table 4). Because point type had the most support of topographic variables for influencing population growth rate in the pre-post dataset (Section 3.3), we modeled the additive and interactive response to years-post-harvest and point type. We did not test vegetation variables because we sampled vegetation once post-harvest rather than each year post-harvest. Because some points were monitored post-harvest for one year while others were monitored for two- or three-years post-harvest, we modeled the multiple years of post-harvest abundance data in a single-season format. This approach required us to use a closed population $N$-mixture model (Royle, 2004), which assumes closure among the three within-season visits, but the population is open across years. This approach achieves a larger effective sample size and is useful in cases with limited data or unequal sample sizes (Burnett and Roberts, 2015; Fuller et al., 2016). While this modeling structure ignores some of the variability by assuming that
Table 4

Model selection process to determine the most parsimonious $N$-mixture models that explain change in Cerulean Warbler (Setophaga cerulea) abundance from one year post-harvest to three years post-harvest at seven study areas in Kentucky, Virginia, and West Virginia 2013-2017. Static $N$-mixture models for 187 points with post-harvest data are shown. Models are presented in order of AICc value with the top model (i.e., lowest AICc value) first. $\mathrm{K}$ is the number of parameters in a model, AICc is the Akaike's Information Criterion value for small sample sizes, which measures the fit of a model relative to other models, $\triangle \mathrm{AICc}$ is the difference between each model's AICc value and the lowest AICc value in the candidate set, and wi is the Akaike weight of each model in relation to the entire candidate set. Codes for variables in models are defined in Table 2.

\begin{tabular}{|c|c|c|c|c|}
\hline Model $^{1}$ & $\mathrm{~K}$ & AICc & $\triangle \mathrm{AICc}$ & $\mathrm{w}_{\mathrm{i}}$ \\
\hline $\begin{array}{l}\mathrm{p}(\text { obsv }+ \text { ord }+ \text { tssr }) \lambda \\
\quad(\mathrm{SA}+\text { year }+ \text { pttype }+ \text { yph })\end{array}$ & 19 & 1451.55 & 0.00 & 0.55 \\
\hline $\mathrm{p}(\mathrm{obsv}+$ ord + tssr $) \lambda(\mathrm{SA}+$ year + pttype $)$ & 18 & 1452.48 & 0.92 & 0.34 \\
\hline $\begin{array}{l}\mathrm{p}(\text { obsv }+ \text { ord }+ \text { tssr }) \lambda \\
\quad(\mathrm{SA}+\text { year }+ \text { pttype } * \text { yph })\end{array}$ & 21 & 1454.89 & 3.34 & 0.10 \\
\hline $\mathrm{p}(\mathrm{obsv}+$ ord + tssr) $\lambda(\mathrm{SA}+$ year $+\mathrm{yph})$ & 17 & 1460.35 & 8.80 & 0.01 \\
\hline
\end{tabular}

${ }^{1} \mathrm{p}=$ detection probability, $\lambda=$ abundance.

abundance from each point count is independent across years, it is still reasonable for estimating temporal trends conditional on the explicit habitat covariates (Table 2; Linden and Roloff, 2013; Kéry and Royle, 2015; Ahlering and Merkord, 2016; Fuller et al., 2016). As such, we added a years-post-harvest covariate for each point so that we could evaluate the post-only data according to our objectives. We had postharvest data from 187 points across the seven study areas (Nareff et al., 2019 dataset 2) resulting in 474 independent samples (one year postharvest $\mathrm{n}=187$, two years post-harvest $\mathrm{n}=164$, three years postharvest $\mathrm{n}=123)$. Closed population $N$-mixture models estimate two parameters: abundance and detection probability. We included study area and calendar year in the abundance parameter for all models to account for inherent differences in Cerulean Warbler abundance among study areas and calendar years because harvests occurred in different years among study areas. We used the "ranef" function as described in Section 2.5.5.

\subsubsection{Assessing abundance-environmental variable relationships}

For both datasets, we used abundance from supported models to graphically examine the change in pre- and post-harvest abundance or post-harvest abundance of Cerulean Warblers in relation to any variables that appeared within supported models. In doing so, we could examine confidence intervals and visually summarize results to aid forest managers in making management decisions. We evaluated the relationships between population growth and influential variables by assessing the sign and $95 \%$ confidence intervals of the slope ( $\beta$ coefficient).

\section{Results}

\subsection{Vegetation}

Within each harvest stand on each study area except GL, basal area was decreased substantially in relation to the unharvested reference stands. At pre-post study areas, basal area at harvested points was reduced by $13 \%$ at GL and by $35-60 \%$ (mean $44 \%$ ) at the remaining study areas. At the seven study areas, basal area in reference stands was 24.4-37.8 $\mathrm{m}^{2} / \mathrm{ha}$. In harvested stands, post-harvest basal area was $7.0-25.3 \mathrm{~m}^{2} /$ ha at harvest interior points and $18.1-27.0 \mathrm{~m}^{2} /$ ha at harvest edge points. We recorded 39 tree species pre-harvest and 44 species post-harvest. Pre-harvest, the five tree species with greatest basal area, starting with the greatest, were northern red oak, red maple, chestnut oak, tulip poplar, and white oak. Post-harvest, the same five species were dominant, but chestnut oak accounted for the most stems, followed by red maple and northern red oak. 


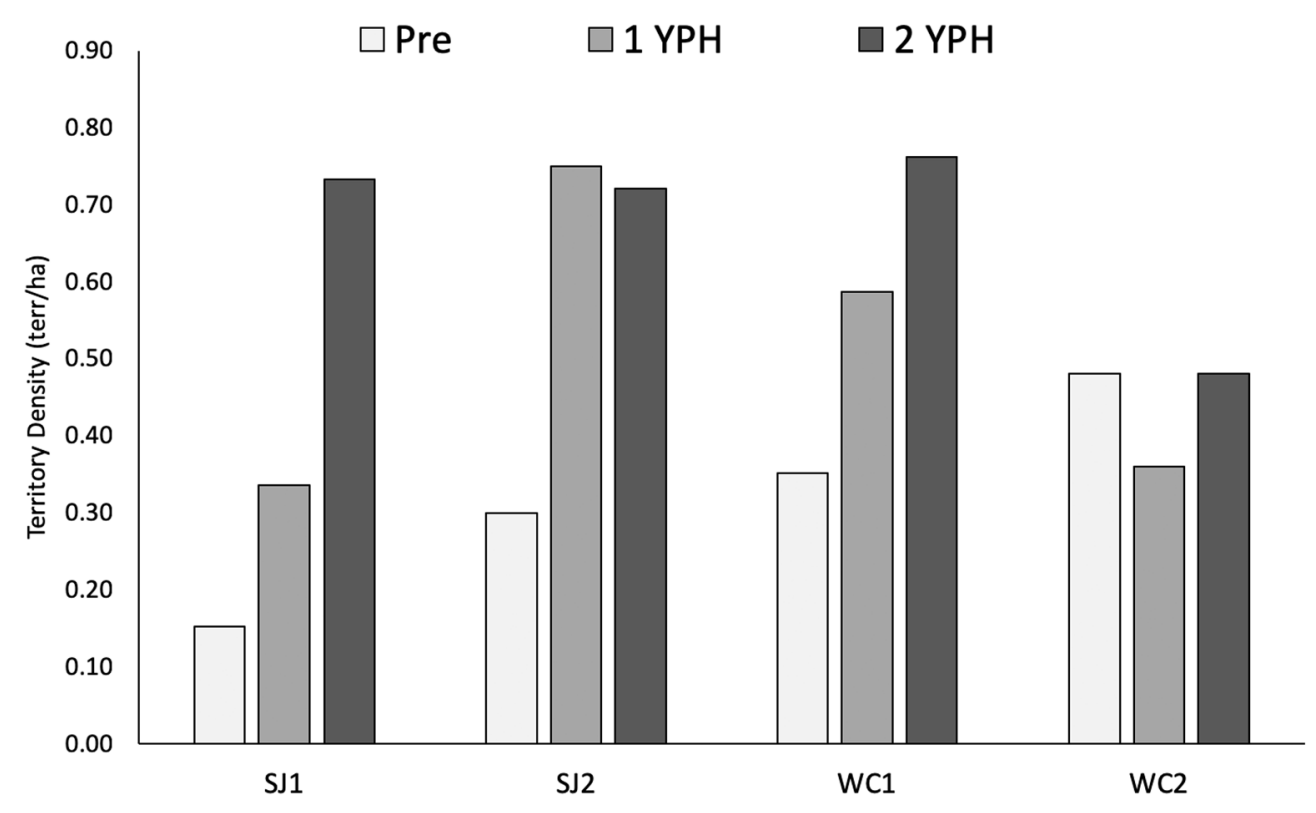

Fig. 3. Cerulean Warbler territory density by territory mapping plot pre-harvest (Pre; 2013-2014), one year post-harvest (1 YPH; 2014-2015), and two years post-harvest (2 YPH; 2015-2016) for this investigation of Cerulean Warbler (Setophaga cerulea) response to harvests implemented as operational silvicultural prescriptions. Study areas were Stonewall Jackson Lake Wildlife Management Area (SJ) and Wolf Creek (WC) at Elk River Wildlife Management Area in West Virginia.

\subsection{Territory density}

Pre-harvest, among the four territory mapping plots, we delineated 20 territories in $2013(0.30 \pm 0.06$ territory/ha) and 14 territories in 2014 (0.28 \pm 0.08 territory/ha). Post-harvest, we delineated 33 territories one year post-harvest $(0.49 \pm 0.10$ territory/ha) and 44 territories two years post-harvest $(0.66 \pm 0.06$ territory/ha). A ShapiroWilk test indicated the territory density data were normally distributed ( $W=0.93, P=0.43$ ) and a Mauchly's test indicated the data did not violate the assumption of sphericity ( $W=0.77, P=0.77$ ). Territory density differed significantly among the three pre-post-harvest year categories $\left(F_{2,9}=4.3, P=0.048\right)$. Post hoc tests indicated the $51 \%$ change in territory density between pre-harvest and one-year postharvest $(P=0.34)$ and $32 \%$ change between one-year and two-years post-harvest $(P=0.36)$ were not significant, whereas the $100 \%$ increase between pre-harvest and two years post-harvest was statistically significant $(P=0.04)$. The change in territory densities by years-postharvest was variable depending on pre-harvest density with lower densities increasing more than higher densities (Fig. 3).

\subsection{Pre-post-harvest abundance}

Pre-harvest abundance influenced post-harvest abundance at harvest interior and harvest edge points. Where increases in post-harvest modeled abundance did occur $(n=21)$, the greatest increases occurred where pre-harvest abundance was $<2.0$ birds/point (Fig. 4). Of the 32 harvested points where modeled abundance decreased or did not change, $66 \%(n=21)$ were harvest edge points and $34 \%(n=11)$ were harvest interior points. Some of these points (41\%) had modeled preharvest abundance $<1$ and several close to 0 .

All survey covariates were in the top detection probability model, and thus were included in final analyses (Table 3). For model set 1 , the top model included point type as the only influence on abundance and resulted in $69 \%$ of model weight. Slopes of $\beta$ coefficients from the top model were positive for harvest interior and harvest edge and negative for reference points, but 95\% CIs overlapped zero for all point types (Table 5). Modeled abundance pre-harvest at harvest interior points (2.2 birds/point, $95 \% \mathrm{CI}=1.4-3.0$ ), harvest edge points (1.8 birds/ point $95 \% \mathrm{CI}=1.3-2.3$ ), and reference points (1.8 birds/point $95 \%$

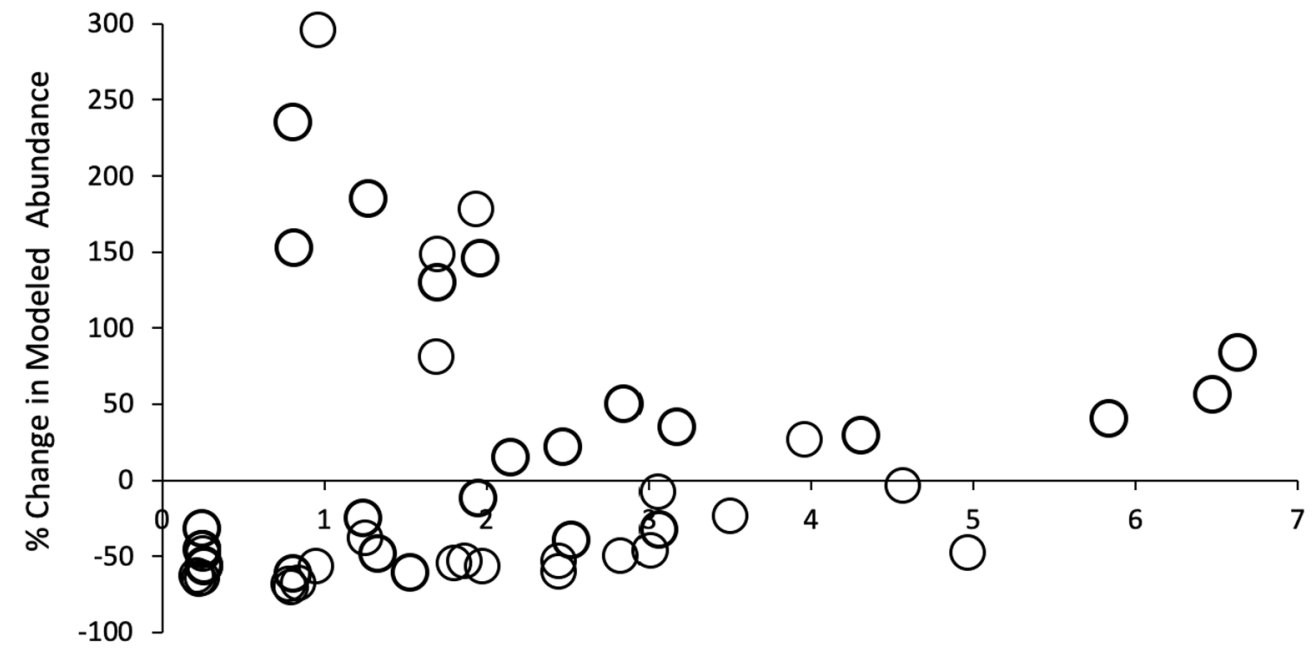

Fig. 4. Percent change in estimated abundance of Cerulean Warblers (Setophaga cerulea) following tree harvest in forested stands in Kentucky, Virginia, and West Virginia during 2013-2017. The hierarchical model used to estimate abundance included study area as a covariate for initial abundance, point type as a covariate for population growth rate, and observer, ordinal date, noise, and time-since-sunrise as covariates for detection probability. Estimated changes in abundance are based on abundance at 54 harvest interior and harvest edge points. Three points with change $>300 \%(709 \%, 823 \%$ and $1260 \%$ at harvest interior points) were omitted from the graph to more clearly show the relationship with pre-harvest abundance.

Pre-harvest Modeled Abundance 
Table 5

Parameter estimates, standard errors (SE), 95\% lower and upper confidence intervals (CI), and P-values from top ranked $N$-mixture models (see Table 3 ) estimating population growth of Cerulean Warblers (Setophaga cerulea) at 114 points at five harvested study areas in Kentucky, Virginia, and West Virginia 2013-2017.

\begin{tabular}{lllll}
\hline Parameter & $\beta$ estimate & SE & Lower 95\% CI & Upper 95\% CI \\
\hline $\begin{array}{l}\text { Model set 1: point type } \\
\text { pttype }\end{array}$ & & & \\
Harvest interior & 0.6 & 0.3 & -0.1 & 1.2 \\
Harvest edge & 0.1 & 0.4 & -0.6 & 0.8 \\
Reference & -0.6 & 0.3 & -1.2 & 0.1 \\
Model set 2: vegetation variables & & & & \\
bapref & 1.3 & 0.6 & 0.04 & 2.5 \\
balarge & 1.2 & 0.7 & -0.2 & 2.6 \\
\hline
\end{tabular}

1 bapref = percentage of basal area that was preferred tree species (white oak [Quercus alba], chestnut oak [Q. prinus], sugar maple [Acer saccharum], and hickories [Carya spp.]) and balarge = percentage of basal area that was $\geq 40.6 \mathrm{~cm}$ diameter at breast height.

* Confidence intervals do not include zero, indicating significance.

$\mathrm{CI}=1.4-2.2)$ was similar. Post-harvest, abundance at harvest interior points ( 3.3 birds/point, $95 \% \mathrm{CI}=2.1-4.5$ ) was greater than abundance at reference points (1.4 birds/point $95 \% \mathrm{CI}=1.0-1.8$ ) and abundance at harvest edge points ( $1.7 \mathrm{birds} /$ point, $95 \% \mathrm{CI}=1.1-2.3$ ) remained similar to pre-harvest abundance (Fig. 5). The models testing the additive response of point type and Beers aspect $(\triangle \mathrm{AICc}=2.62)$ and point type and slope position $(\triangle \mathrm{AICc}=3.40)$ on population growth rate had less support for the pre-post data $(\triangle \mathrm{AICc}=2-7$; Burnham and Anderson, 2011; Table 3). These models represented $19 \%$ and $13 \%$ of model weight, respectively, suggesting that population growth rate in response to harvest was less influenced by slope position and aspect than point type alone.

For vegetation covariates, one model with percent of basal area that was preferred tree species (bapref) and one model with percent of basal area that was large diameter trees (balarge) had the most support for explaining abundance (Table 3). These models had $37 \%$ and $20 \%$ of model weight, respectively. The positive slope of the $\beta$ coefficient for bapref and a $95 \%$ confidence interval that did not include zero indicated a significant positive linear relationship between Cerulean Warbler abundance and increasing percent of bapref (Table 5; Fig. 6A). Positive change in abundance from pre- to post-harvest (Fig. 6B) and positive population growth (Fig. 6C) were predicted to occur where percent of bapref was generally $>50 \%$.

Cerulean Warbler abundance had a positive linear relationship with increasing percent of the basal area that was large diameter trees (Fig. 7A) indicated by the positive slope of the $\beta$ coefficient for balarge; however, the $95 \%$ confidence interval overlapped zero (Table 5). Positive change in abundance at the point level, from pre- to post-harvest (Fig. 7B) and positive population growth (Fig. 7C) were predicted to occur where percent of balarge was generally $>45 \%$ and $>50 \%$, respectively.

\subsection{Post-harvest-only abundance}

The top detection model for post-harvest only data, included observer, ordinal date, and time-since-sunrise covariates and thus were included in final analyses (Table 4). The model selection found the point type + years-post-harvest and point type models $(\triangle \mathrm{AICc}=0.89)$ had the most support compared to the two other models (55\% and 34\% of Akaike weight, respectively; Table 4). We predicted slopes of harvest interior and harvest edge points relative to reference points and reference points relative to harvest interior points. Confidence intervals (95\%) of $\beta$ coefficients from the top model for harvest interior (positive slope) and reference (negative slope) points did not include zero, suggesting their significance in explaining population growth, whereas the confidence interval for harvest edge (positive slope) points did include zero (Table 6). Modeled abundance at harvest interior points increased slightly from one year post-harvest (mean $=0.9$ birds/point, 95\% $\mathrm{CI}=0.6-1.2)$ to two years post-harvest (mean $=1.5 \mathrm{birds} /$ point, $95 \%$ $\mathrm{CI}=1.0-2.0$ ), but decreased to 0.8 birds/point $(95 \% \mathrm{CI}=0.5-1.1$ ) three-years post-harvest (Fig. 8). Modeled abundance at harvest edge points was relatively similar across years with mean $=0.7$ birds $/$ point $(95 \% \mathrm{CI}=0.4-1.0)$ one year post-harvest, mean $=1.1 \mathrm{birds} /$ point (95\% CI $=0.6-1.6)$ two years post-harvest, and mean $=0.6$ birds/ point (95\% CI $=0.3-0.9$ ) three-years post-harvest. Relative to harvest interior points, modeling indicated a significant negative slope at reference points; however, actual modeled abundance increased slightly between one (mean $=0.6$ birds/point, $95 \% \mathrm{CI}=0.4-0.8$ ) and two years post-harvest $($ mean $=1.0$ birds/point, $95 \% \mathrm{CI}=0.8-1.2$ ) and decreased three years post-harvest (mean $=0.7$ birds/point, $95 \%$ $\mathrm{CI}=0.5-0.9$ ). Abundances among point types were similar three years post-harvest (Fig. 8).

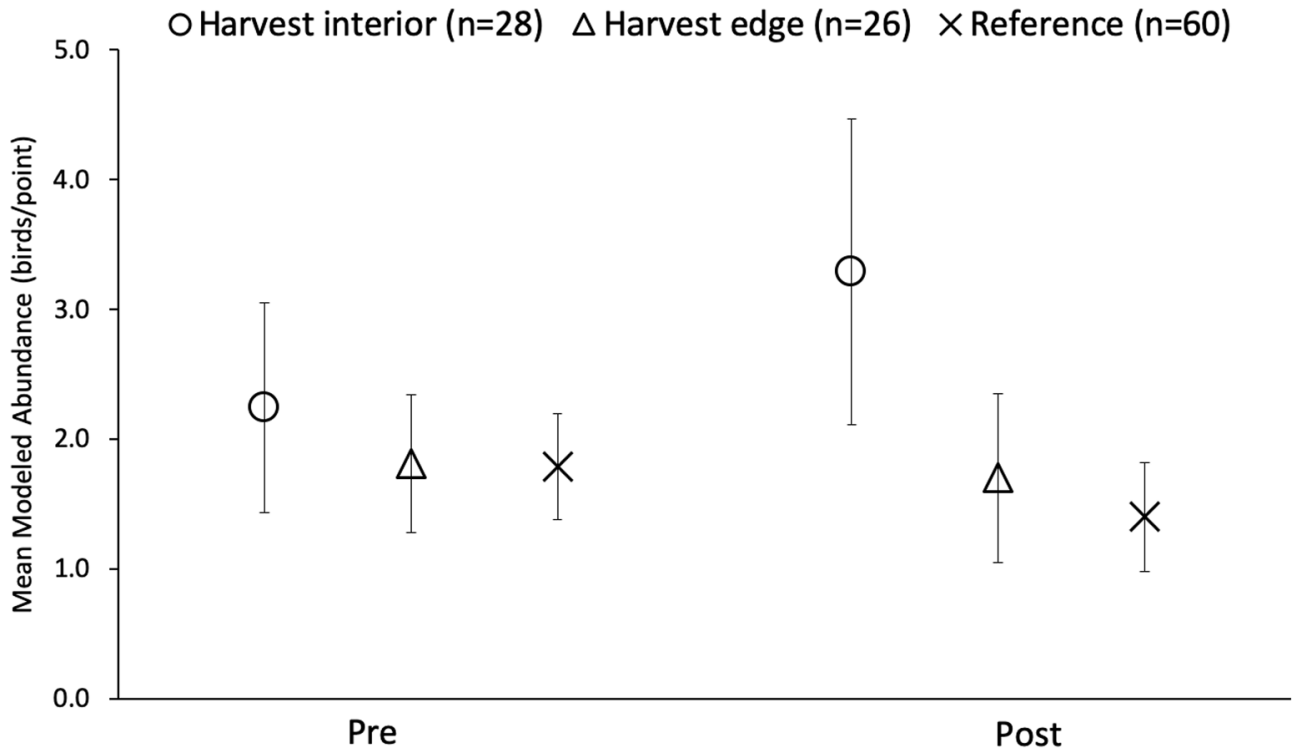

Fig. 5. Pre- and post-harvest Cerulean Warbler (Setophaga cerulea) modeled abundance by point type (harvest interior, harvest edge, reference) at 114 sample points at five harvested study areas in Kentucky, Virginia, and West Virginia 2013-2017. Bars represent $95 \%$ confidence intervals. The hierarchical model used to estimate abundance included study area as a covariate for initial abundance, point type as a covariate for population growth rate, and observer, ordinal date, noise, and timesince-sunrise for detection probability. 


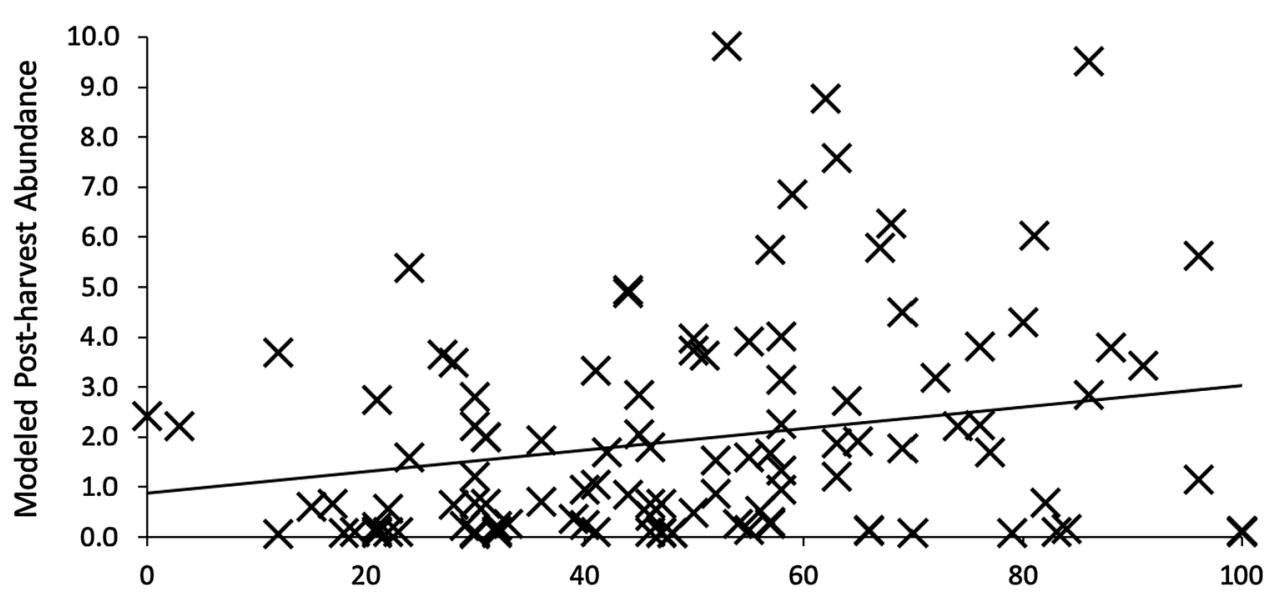

A

\% Basal Area of Preferred Tree Species

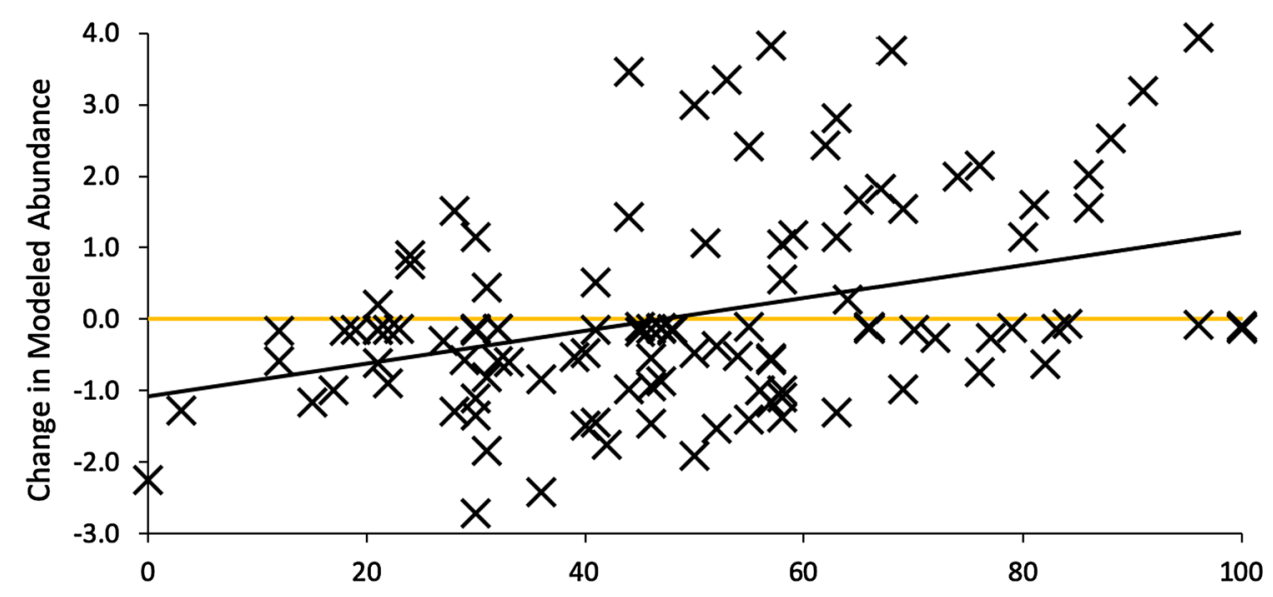

B

\% Basal Area of Preferred Tree Species

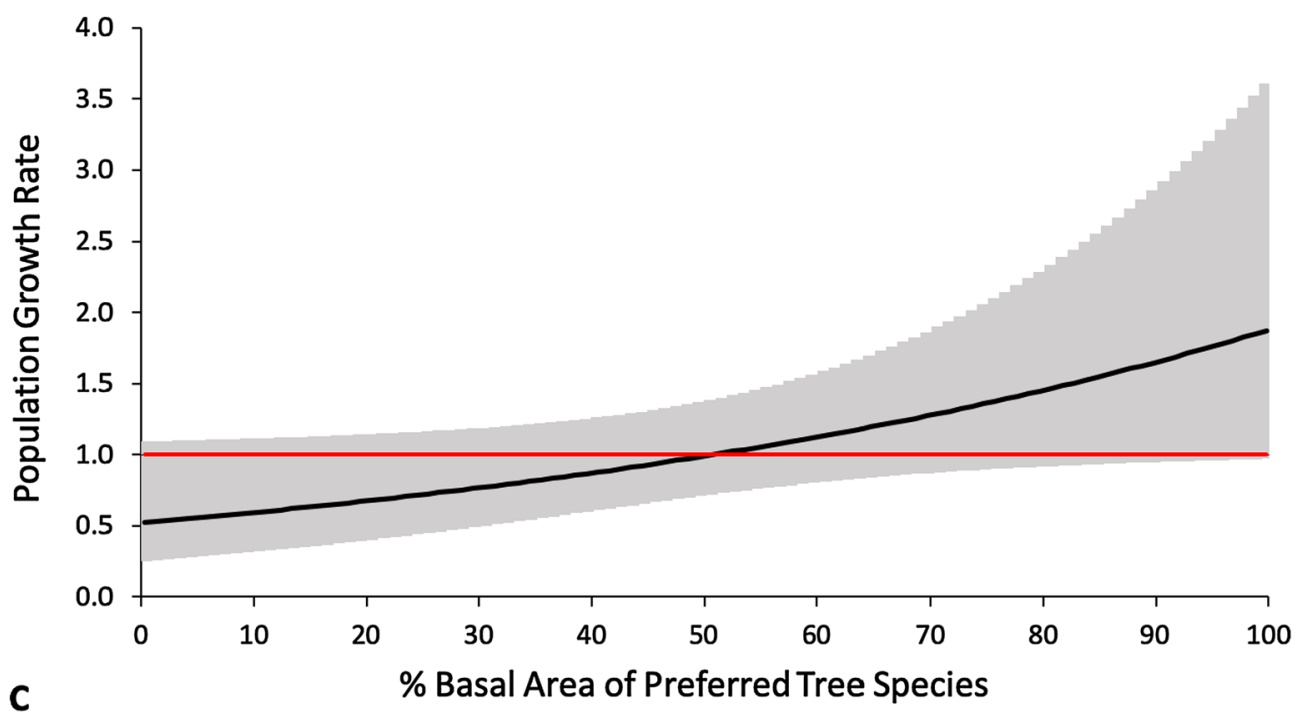

Fig. 6. The three panels show Cerulean Warbler (Setophaga cerulea) modeled abundance or population growth rate (\# birds/ point) at 114 harvest interior, harvest edge, and reference sample points relative to the percentage of basal area that was preferred tree species $\geq 10 \mathrm{~cm}$ dbh at five harvested study areas in Kentucky, Virginia, and West Virginia 2013-2017. Preferred tree species include sugar maple (Acer saccharum), white oaks (Quercus spp.), and hickories (Carya spp.). Post-harvest abundance relationship to percent basal area that is preferred tree species (A), change in abundance pre- to post-harvest (B) and predicted population growth rate with $95 \%$ confidence intervals (C) are shown. The model used to estimate abundance included study area as a covariate for initial abundance, percentage of basal area that was preferred tree species as a covariate for population growth rate, and observer, ordinal date, noise and time-sincesunrise for detection probability.

\section{Discussion}

\subsection{Overall changes in territory density and abundance}

We observed that harvests on state lands that follow the Guidelines (Wood et al., 2013) for operational silviculture in support of Cerulean
Warbler breeding habitat in the central Appalachian region had a positive effect on Cerulean Warbler territory density and abundance at our study areas, at least for the first two years post-harvest. Mean Cerulean Warbler territory density increased $100 \%$ from pre-harvest to two-years post-harvest, which we posit is a result of mid- and understory regeneration. These results corroborate findings from the original 


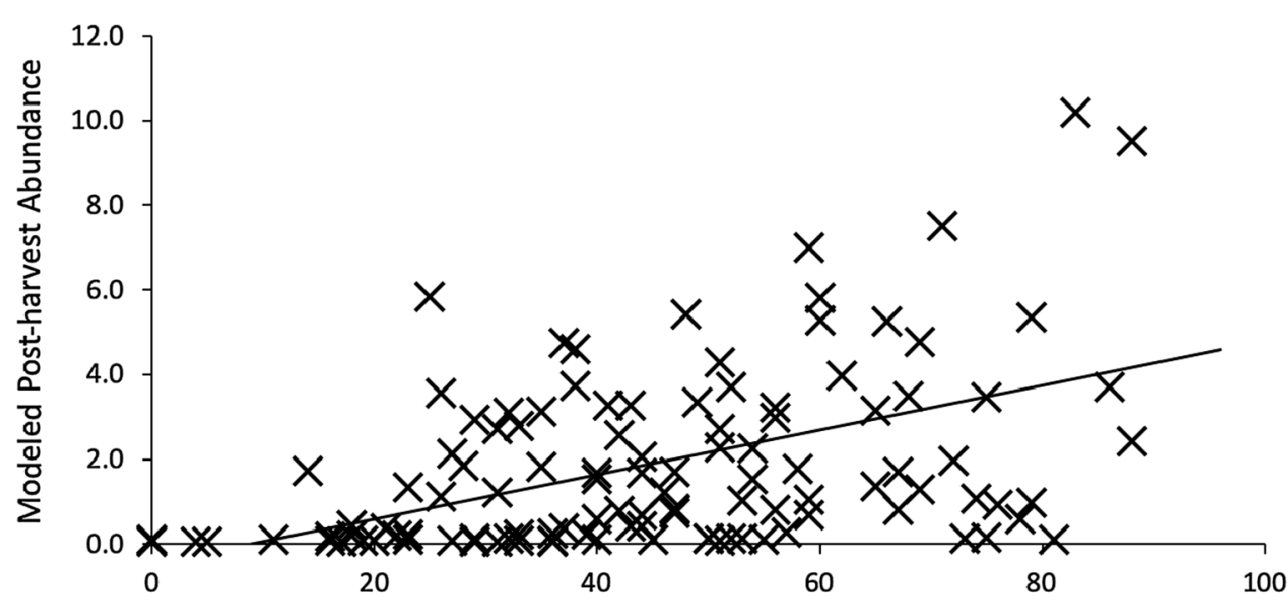

A
Fig. 7. The three panels show Cerulean Warbler (Setophaga cerulea) modeled abundance or population growth rate (\# birds/ point) at 114 harvest interior, harvest edge, and reference sample points relative to the percentage of basal area that was large diameter trees ( $\geq 40.6 \mathrm{~cm} \mathrm{dbh})$ at five harvested study areas in Kentucky, Virginia, and West Virginia 2013-2017. Post-harvest abundance (A), change in abundance pre- to post-harvest (B), and predicted population growth rate with $95 \%$ confidence intervals (C) are shown. The model used to estimate abundance included study area as a covariate for initial abundance, percentage of basal area that was large diameter trees as a covariate for population growth rate, and observer, ordinal date, noise, and timesince-sunrise for detection probability.

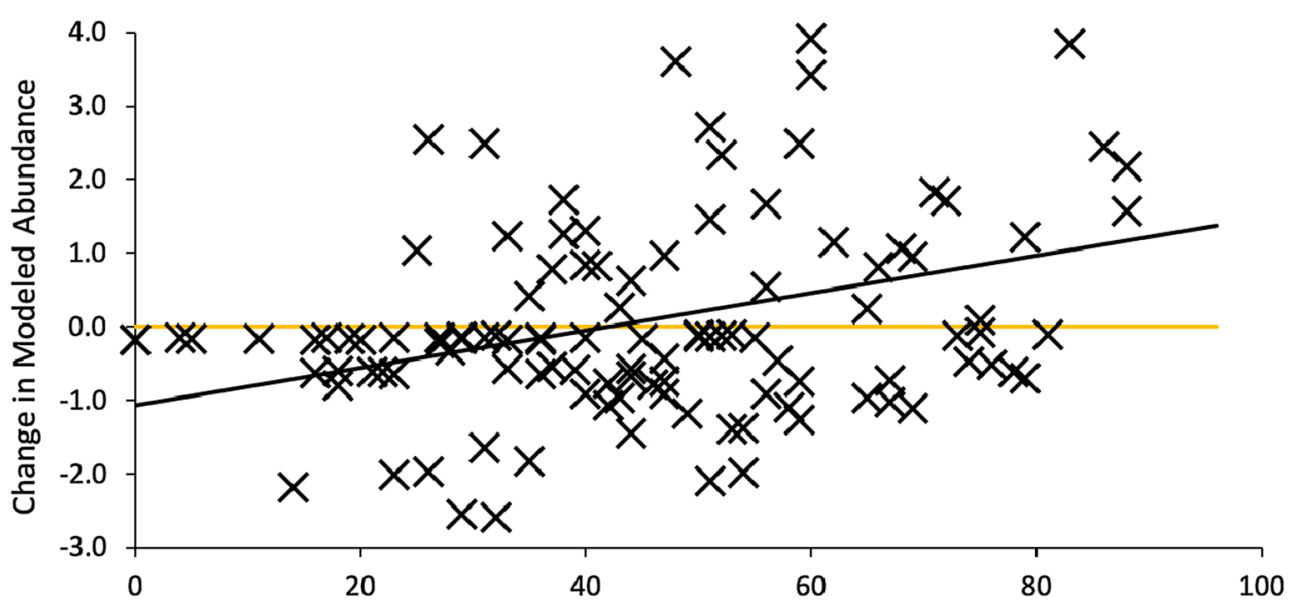

B

\% Basal Area of Large Diameter Trees

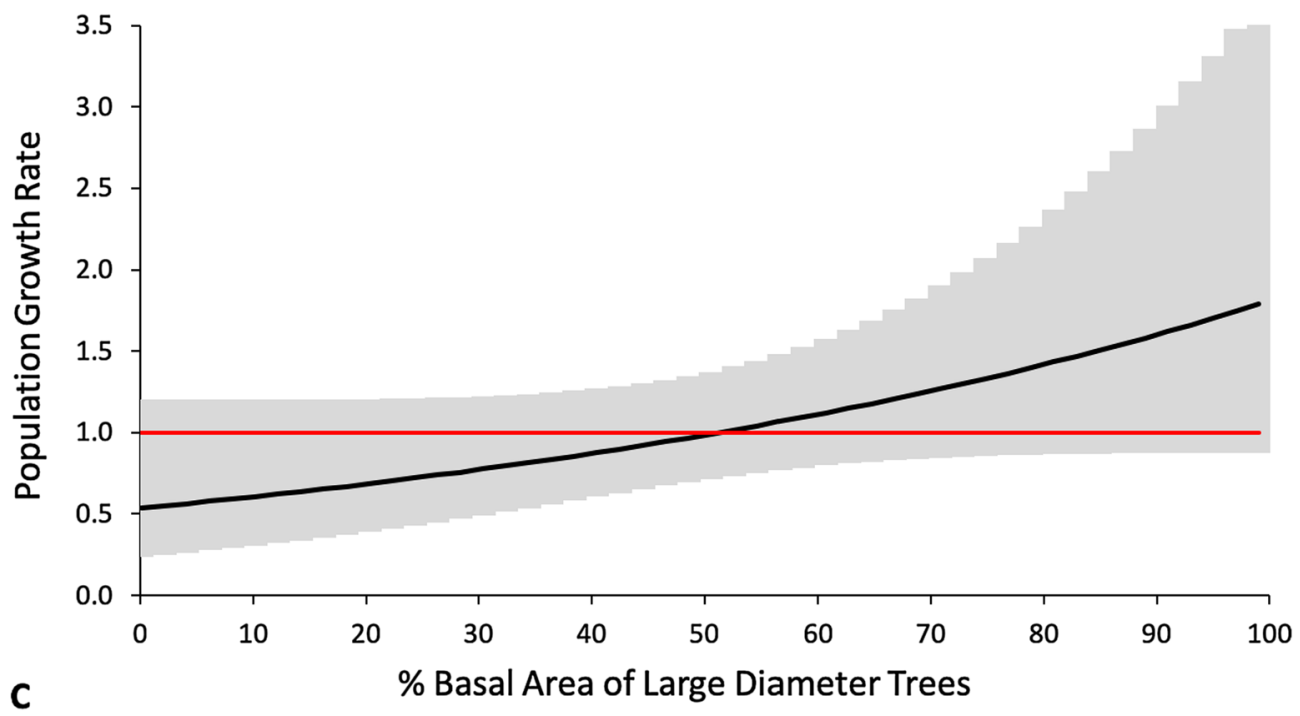

experimental study (Sheehan et al., 2013). A diversity of habitat types is selected by the different sexes and life stages of the species and different vegetative strata are used for different activities (e.g., Bakermans and Rodewald, 2009; Boves et al., 2013a; Wood and Perkins, 2012; Raybuck, 2016). Accordingly, the full breeding and post-fledging season of the bird must be considered when managing for breeding habitat. Harvest mosaics with a range of canopy disturbances, such as the ones in our study, may provide this variety of habitat for the Cerulean Warbler (Boves et al., 2013a).

The previous regional study in the central Appalachian region determined that territory mapping plots with high pre-harvest territory density may have been at or near saturation and harvesting did not 
Table 6

Parameter estimates, standard errors (SE), 95\% lower and upper confidence intervals (CI), and P-values from the top ranked N-mixture model estimating population growth of Cerulean Warblers (Setophaga cerulea) at 187 points at seven harvested study areas in Kentucky, Virginia, and West Virginia 2013-2017.

\begin{tabular}{lllll}
\hline Parameter & $\beta$ estimate & SE & Lower 95\% CI & Upper 95\% CI \\
\hline pttype + yph & & & & \\
Harvest interior* & 0.5 & 0.2 & 0.2 & 0.8 \\
Harvest edge & 0.2 & 0.2 & -0.1 & 0.6 \\
Reference & -0.5 & 0.2 & -0.8 & -0.2 \\
yph & 0.4 & 0.2 & -0.1 & 0.8 \\
\hline
\end{tabular}

* Confidence intervals do not include zero, indicating significance.

provide additional space for densities to increase (Boves et al., 2013b, Sheehan et al., 2013). The Guidelines suggested limited management where density is $>5$ territory $/ 25$ ha $(0.20$ territory/ha; Wood et al., 2013). However, we observed increases post-harvest where pre-harvest densities were greater than this, so management may be most beneficial where densities are $<10$ territory/25 ha ( 0.40 territory/ha), or adjacent to stands with high densities of Cerulean Warblers. Three of the four territory mapping plots in our study increased pre- to one year post-harvest, with one plot increasing substantially and two increasing moderately (Fig. 3). The plot with the highest pre-harvest territory density decreased in the first-year post-harvest and then returned to pre-harvest density two years post-harvest. This latter plot had moderate pre-harvest density ( 0.46 territory/ha), suggesting that it may have been close to saturation and harvesting did not improve habitat.

Some of the points with weak or negative responses in change in modeled abundance (Fig. 4) had modeled pre-harvest abundance $<1.0$ birds/point and close to 0 . These points were all at GL and HI and may indicate these study areas and adjacent stands did not have enough birds to respond to the harvests. Grayson Lake and HI had the lowest proportions of points with Cerulean Warblers pre-harvest when summarizing raw data $(29 \%$ and $11 \%$, respectively, compared to $>55 \%$ at GA, SJ, and WC). The Guidelines (Wood et al., 2013) recommend implementing harvests where Cerulean Warblers are present, but not abundant, and our modeling results support this. Where there were increases in modeled abundance at our post-harvest points, the greatest increases occurred where Cerulean Warblers were present, but not abundant pre-harvest.

Although point type was included in the top model for explaining

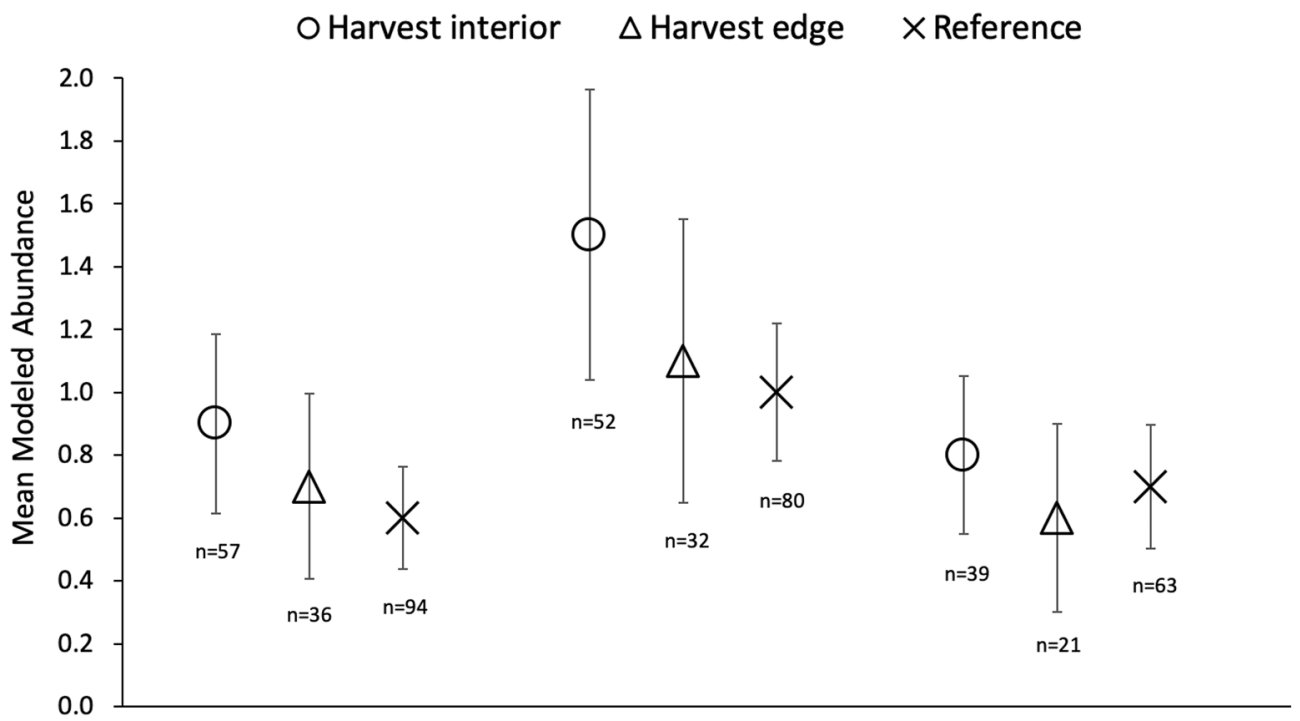

Cerulean Warbler abundance at our pre-post study areas, abundance did not change significantly by point type (it approached significance; $P=0.08$; Fig. 5). However, when modeling years-post-harvest, change in abundance was significant and mean abundance was higher at harvest interior points than reference points (Fig. 8). Since we did observe a substantial increase in territory densities post-harvest, the lack of significant changes in abundance at pre-post study areas is likely the result of high variability at the point level as indicated by the wide CI for harvest interior points.

\subsection{Response to topographic metrics}

Because our harvests were applied to a broad range of available topographic characteristics including coves, middle slope positions, and ridgelines, all available aspects, and harvests were applied to one physiographic region not included in the original study, we can update and expand the scope of inference for the Guidelines. Cerulean Warbler habitat selection varies throughout the breeding range (e.g., bottomland forests in the southeastern US), but in the central Appalachian region in mature forest stands, the species is typically more abundant on middle and upper slopes and ridgetops, at north- to northeast-facing aspects (Hamel, 2000; Weakland and Wood, 2005; Wood et al., 2006; Newell and Rodewald, 2012). These topographic characteristics inherently result in canopy gaps particularly through windthrow. However, our study indicated that slope position and Beers aspect, when tested in models with point type, were not as influential as point type alone on post-harvest abundance of Cerulean Warblers (Tables 2 and 4). During early data exploration, we also tested interactive models of point type with slope position and point type with Beers aspect. However, these relationships were not important to change in Cerulean Warbler modeled abundance. This further supports our results, which indicated that timber harvests on less preferred slope positions and aspects can provide habitat for Cerulean Warblers, at least for two years post-harvest, during which time we saw increases in abundance and territory density. We observed that whereas harvests on the Cerulean Warbler's preferred slope positions and aspects provided breeding habitat for the birds, these same treatments on less preferred topographic characteristics also attracted Cerulean Warblers for multiple seasons. Thus, our study expands on the understanding of Cerulean Warbler response to forest harvesting.
Fig. 8. Mean Cerulean Warbler (Setophaga cerulea) modeled abundance (birds/point) at 187,164 , and 123 sample points at seven harvested study areas in Kentucky, Virginia, and West Virginia 2013-2017, one, two, and three years-post-harvest, respectively. Bars represent $95 \%$ confidence intervals. The model used to estimate abundances post-harvest included study area, point type (harvest interior, harvest edge, reference), years-post-harvest, and calendar year as covariates for post-harvest abundance, and observer, ordinal date, and time-since-sunrise for detection probability. Two points were on the edge of a partial harvest in the first year post-harvest and then true harvest points two years post-harvest after the harvest was complete. This resulted in the numbers of harvest interior points to be the same for the first two years post-harvest. 


\subsection{Response to vegetation}

Cerulean Warbler abundance showed a positive, albeit weak, relationship with percent basal area of preferred tree species (Fig. 6). The current Guidelines suggest retention of large diameter trees of preferred tree species because Boves et al. (2013a) found nests typically were in trees that averaged $35-48 \mathrm{~cm}$ dbh. Our results confirm that the presence of white oaks, sugar maple, and hickories is positively associated with Cerulean Warbler abundance and population growth rates in the central Appalachian region and provide management targets for percent retention. While percentage of large diameter $(\geq 40.6 \mathrm{~cm} \mathrm{dbh})$ trees was an important variable in our modeling (Table 3), the relationship with Cerulean Warbler abundance was not significant (Table 5). Cerulean Warbler selection of large diameter trees in the central Appalachian region is well-documented (e.g., Weakland and Wood, 2005; Buehler et al., 2008; Hartman et al., 2009; Boves et al., 2013b). This relationship may be due to the structure of the tree itself, or the forest conditions where larger trees typically grow (i.e., old growth forests with canopy gaps). It is possible that harvests may have alleviated some of the dependence on large diameter trees for nesting by opening the canopy on a broader range of slope positions and aspects, without relying on large diameter trees for that to happen (i.e., windthrown trees creating gaps). Cerulean Warblers may select larger diameter trees because that is what tends to be available in mature forests (Hamel, 2000). If the tree species is more important than the size of tree, you would expect to see the results we observed in our study.

\subsection{Response to years-post-harvest}

Years-post-harvest can be important in influencing Cerulean Warbler abundance because canopy closure over time limits the length of time a harvest is beneficial (Sheehan et al., 2013). We observed an overall increase in abundance and territory density one and two years post-harvest (although response varied among territory mapping plots and points). During the second year following harvest, regeneration of the understory likely provided higher quality foraging and refuge habitat for nesting females, post-breeding adults, and fledglings (Pagen et al., 2000; Vitz and Rodewald, 2006; Boves et al., 2013a; Porneluzi et al., 2014; Raybuck, 2016; Ruhl et al., 2018). Abundance subsequently decreased three years post-harvest. Previous research in the central Appalachian region observed higher post-harvest abundance up to four years post-harvest in moderate to heavy harvests, although the response to lighter harvests decreased across time more rapidly (Boves et al., 2013b, Sheehan et al., 2013). The increase of sunlight into the open canopy for two growing seasons may have allowed the canopy trees in the lighter harvests to grow enough to reduce the number and size of gaps (Perkey et al., 2011; Himes and Rentch, 2013) such that the openings were no longer appropriate for Cerulean Warbler territories. The decline we observed three years post-harvest may have been driven by the small number of points sampled three years post-harvest, many of which were at our Kentucky (GL) study area. Basal area at GL was reduced by only $16 \%$ post-harvest, compared to $35-60 \%$ (mean $44 \%$ ) at other study areas. By the third-year post-harvest, any harvest at GL was visually undetectable in the field because the canopy had closed. Cerulean Warbler abundance at GL was the same pre-harvest through two years post-harvest after which it decreased in the third-year post-harvest. Despite the relatively short-term benefit to Cerulean Warblers indicated here and in other studies (Boves et al., 2013b, Sheehan et al., 2013), harvesting in a spatial and temporal mosaic may provide overall long-term benefits to Cerulean Warblers, as a variety of seral stages will be available across the landscape at any given time. Further, shelterwood harvests where the residual canopy is removed in a successive harvest 5-10 years after the initial cut, would not be expected to provide long-term benefits to the species.

\section{Conclusions}

As a species of conservation concern throughout its range, the Cerulean Warbler requires specific management strategies (Roth and Islam, 2008; Boves et al., 2013a) and a better understanding of its response to forest management (Hamel, 2000). Boves et al. (2013a) found that some preferred habitat features within territories actually led to a decrease in Cerulean Warbler nest success, indicating that local conditions need to be considered when managing for this species. In the absence of forests managed with harvesting practices that influence canopy structure, Cerulean Warblers in the central Appalachian region use older, heterogeneous forests, which provide appropriate conditions for breeding (Oliarnyk and Robertson, 1996; Bakermans and Rodewald, 2009; Boves et al., 2013a; Perkins and Wood, 2014). Our harvests created appropriate Cerulean Warbler habitat in otherwise less preferred stands by decreasing the basal area to within the range recommended by the Guidelines, which opened the canopy while simultaneously retaining large specimens of tree species preferred by Cerulean Warblers.

Taking no forest management action in order to wait for the natural development of older, heterogeneous stands is not expedient when managing for a species of conservation concern, such as the Cerulean Warbler. Development of old growth forest conditions can take hundreds of years and in that time, this species could go extinct. The PIF predicts a $50 \%$ reduction in the Cerulean Warbler population within the Appalachian Mountains Bird Conservation Region, where our study areas occur, in fewer than 19 years (Rosenberg et al., 2016). Harvests with the conditions described here appear to be an effective management tool for creating the canopy structure and regeneration needed by breeding Cerulean Warblers for at least two years post-harvest. Based on our research, harvests appear most beneficial for increasing abundance where Cerulean Warblers are present but not abundant preharvest (Fig. 4). Resources may be better directed towards enhancing habitat and increasing territory density in stands with low densities. Fortunately, managing breeding habitat for Cerulean Warblers simultaneously provides management opportunities for popular game species such as Wild Turkey (Meleagris gallopavo), Ruffed Grouse (Bonasa umbellus), and white-tailed deer (Odocoileus virginianus). These game species benefit from complex forest structure with mast-producing trees, interspersed with fields and young forests to satisfy habitat needs year-round and for all age classes and sexes (e.g., Thogmartin, 2001; Tirpak et al., 2010). The results of our study also show that Wildlife Management Areas and State Forests, which are managed for multiple types of public use, may simultaneously be managed for declining species of conservation need.

Our study expands on the current knowledge of Cerulean Warbler breeding habitat in the central Appalachian region by broadening management opportunities within the landscape. Our results imply there are opportunities to create or manage Cerulean Warbler breeding habitat by implementing management practices throughout forest landscapes, and not limit management to specific topographic characteristics. We also identified management targets for size and composition of basal area. Changes in vegetation structure via timber harvesting appear to be more influential on Cerulean Warbler abundance and territory density and these needs could be incorporated into silvicultural prescriptions with objectives other than non-game species conservation.

\section{Acknowledgments}

This study was conducted on state-owned public land and we appreciate the cooperation and especially the implementation of the harvests by West Virginia Division of Natural Resources, Virginia Department of Game and Inland Fisheries, West Virginia Division of Forestry, and the Kentucky Wildlife Resources Commission. Thanks to the many field technicians and biologists who collected data. We thank 
Kyle Aldinger and two anonymous reviewers for helpful comments on this manuscript. Use of trade, firm, or product names does not imply endorsement by the U.S. Government.

\section{Funding}

This work was supported by the West Virginia Division of Natural Resources (grant numbers 10018024.2.1000690W, 10018024.1.1000637W, 10016904.1.1000596W), Virginia Department of Game and Inland Fisheries (grant number EP2366542), U.S. Geological Survey (grant numbers 10016347.1.1005752R, 1434-00HQ-RU-1573), and Pennsylvania Game Commission (grant number 10018688.1.1000664W).

\section{Appendix A. Supplementary material}

Supplementary data to this article can be found online at https:// doi.org/10.1016/j.foreco.2019.05.062.

\section{References}

Ahlering, M.A., Merkord, C.L., 2016. Cattle grazing and grassland birds in the northern tallgrass prairie. J. Wild. Manage. 80, 643-654. https://doi.org/10.1002/jwmg. 1049.

Bakermans, M.H., Rodewald, A.D., 2009. Think globally, manage locally: the importance of steady-state forest features for a declining songbird. For. Ecol. Manage. 258, 224-232. https://doi.org/10.1016/j.foreco.2009.04.010.

Barg, J.J., Aiama, D.M., Jones, J., Robertson, R.J., 2006. Within-territory habitat use and microhabitat selection by male Cerulean Warblers (Dendroica cerulea). Auk 123 , 795-806. https://doi.org/10.1642/0004-8038(2006) 123[795:WHUAMS]2.0.CO;2.

Barker, R.J., Schofield, M.R., Link, W.A., Sauer, J.R., 2018. On the reliability of $N$-mixture models for count data. Biometrics 74, 369-377. https://doi.org/10.1111/biom. 12734.

Beers, T.W., Dress, P.E., Wensel, L.C., 1966. Aspect transformation in site productivity research. J. Forest. 64, 691-692. ftp://gisportal.mt.gov/Maxell/Models/Predictive Modeling_for_DSS_Lincoln_NE_121510/Modeling_Literature/Beersetal1966_Aspect ConversiontoContinuous.pdf.

Bellier, E., Kéry, M., Schaub, M., 2016. Simulation-based assessment of dynamic $N$-mixture models in the presence of density dependence and environmental stochasticity. Methods Ecol. Evol. 7, 1029-1040. https://doi.org/10.1111/2041-210X.12572.

Bibby, C.J., Burgess, N.D., Hill, D.A., 2000. Bird Census Techniques. Academic Press, Toronto, Ontario, pp. 302.

Boves, T.J., Buehler, D.A., Sheehan, J., Wood, P.B., Rodewald, A.D., Larkin, J.L., Keyser, P.D., Newell, F.L., Evans, A., George, G.A., Wigley, T.B., 2013a. Spatial variation in breeding habitat selection by Cerulean Warblers (Setophaga cerulea) throughout the Appalachian Mountains. Auk 130, 46-59. https://doi.org/10.1525/auk.2012.12104.

Boves, T.J., Buehler, D.A., Sheehan, J., Wood, P.B., Rodewald, A.D., Larkin, J.L., Keyser, P.D., Newell, F.L., George, G.A., Bakermans, M.H., Evans, A., Beachy, T.A., McDermott, M.E., Perkins, K.A., White, M., Wigley, T.B., 2013b. Emulating natural disturbances for declining late-successional species: a case study of the consequences for Cerulean Warblers (Setophaga cerulea). PLoS ONE 8, e52107. https://doi.org/10. 1371/journal.pone.0052107.

Buehler, D.A., Giocomo, J.J., Jones, J., Hamel, P.B., Rogers, C.M., Beachy, T.A., Varble, D.W., Nicholson, C.P., Roth, K.L., Barg, J., Robertson, R.J., Robb, J.R., Islam, K., 2008. Cerulean Warbler reproduction, survival, and models or population decline. J. Wild. Manage. 72, 646-653. https://www.fs.usda.gov/treesearch/pubs/30759.

Buehler, D.A., Hamel, P.B., Boves, T., 2013. Cerulean Warbler (Setophaga cerulea), version 2.0. In: Poole, A.F. (Ed.), The Birds of North America. Cornell Lab of Ornithology, Ithaca, NY, USA. https://doi.org/10.2173/bna.511.

Burnett, R.D., Roberts, L.J., 2015. A quantitative evaluation of the conservation umbrella of Spotted Owl management areas in the Sierra Nevada. PLoS ONE 10, e0123778. https://doi.org/10.1371/journal.pone.0123778.

Burnham, K.P., Anderson, D.R., 2002. Model Selection and Multimodel Inference: A Practical Information-Theoretic Approach. Springer, New York, NY.

Burnham, K.P., Anderson, D.R., 2011. AIC model selection and multimodel inference in behavioral ecology: some background, observations, and comparisons. Behav. Ecol. Sociobiol. 65, 23-35. https://link.springer.com/article/10.1007/s00265-0101029-6.

Dail, D., Madsen, L., 2011. Models for estimating abundance from repeated counts of an open metapopulations. Biometrics 67, 577-587. https://doi.org/10.1111/j.1541 0420.2010.01465.x.

Dilts, T. 2015 Topography tools for ArcGIS 10.3 and earlier. < http://www.arcgis.com/ home/item.html?id= b13b3b40fa3c43d4a23a1a09c5fe96b9 >

Duguay, J.P., Wood, P.B., Nichols, J.V., 2001. Songbird abundance and avian nest survival rates in forests fragmented by different silvicultural treatments. Conserv. Biol. 5, 1405-1415. https://www.jstor.org/stable/3061496.

ESRI, 2014. ArcGIS Desktop: Release 10.3. Environmental Systems Research Institute, Redlands, CA.

Fearer, T., 2011. Focal Areas for Golden Wing Warbler and Cerulean Warbler.
Appalachian Mountains Joint Venture. Appalachian Landscape Conservation Cooperative. < https://www.sciencebase.gov/catalog/item/ 5a30a7cde4b08e6a89d5977d >

Fiske, I., Chandler, R., 2011. unmarked: an R Package for Fitting Hierarchical Models of Wildlife Occurrence and Abundance. J. Stat. Softw. 43, 1-23. https://www.jstatsoft. org/article/view/v043i10.

Fuller, A.K., Linden, D.W., Royle, J.A., 2016. Management decision making for fisher populations informed by occupancy modeling. J. Wild. Manage. 80, 794-802. https://doi.org/10.1002/jwmg.21077.

George, G.A., 2009. Foraging Ecology of Male Cerulean Warblers and other Neotropical Migrants. Doctoral Dissertation. West Virginia University, Morgantown, WV, USA.

Haché, S., Pétry, T., Villard, M.-A., 2013. Numerical response of breeding birds following experimental selection harvesting in northern hardwood forests. Avian Conserv. Ecol. 8, 4. https://doi.org/10.5751/ACE-00584-080104.

Hamel, P.B., 2000. Cerulean Warbler Status Assessment. U.S. Department of the Interior, Fish and Wildlife Service, Minneapolis, Minnesota. www.fws.gov/midwest/ endangered/birds/cerw/cerw-sa.pdf.

Hamel, P.B., Dawson, D.K., Keyser, P.D., 2004. How we can learn more about the Cerulean Warbler (Dendroica cerulea). Auk 121, 7-14. https://www.fs.usda.gov/ treesearch/pubs/6384.

Hamel, P.B., Staten, M., Souter, R., Smith III, C.G., Holland, G., 2016. Silviculture for a declining species, Cerulean Warbler: 10-year results of a pilot study in the Mississippi Alluvial Valley. In: Schweitzer, C.J.W.K., Clatterbuck, C.M Oswalt (Eds.), Proceedings of the $18^{\text {th }}$ biennial southern silvicultural research conference. e-Gen. Tech. Rep. SRS-212. U.S. Department of Agriculture, Forest Service, Southern Research Station, Asheville, NC, pp. 614. https://www.fs.usda.gov/treesearch/pubs/50734.

Hartman, P.J., Maehr, D.S., Larkin, J.L., 2009. Habitat selection by Cerulean Warblers in Eastern Kentucky. Wilson Bull. 121, 469-475. https://doi.org/10.1676/07-152.1.

Himes, J.M., Rentch, J.S., 2013. Canopy gap dynamics in a second-growth Appalachian hardwood forest in West Virginia. Castanea 78, 171-184. https://doi.org/10.2179/ 13-006.

Hutto, R.L., 2016. Should scientists be required to use a model-based solution to adjust for possible distance-based detectability bias? Ecol. Appl. 26, 1287-1294. https://doi. org/10.1002/eap.1385.

Johnson, C., Govatski, D., 2013. Forests for the People: The Story of America's Eastern National Forests. Island Press, Washington D.C, pp. 408.

Johnson, C.M., King, R.A. (Eds.), 2018. Beneficial forest management practices for WNS affected bats: voluntary guidance for land managers and woodland owners in the eastern United States. A product of the White-nose Syndrome Conservation and Recovery Working Group, pp. 39.

Joseph, L.N., Elkin, C., Martin, T.G., Possingham, H.P., 2009. Modeling abundance using $N$-mixture models: the importance of considering ecological mechanisms. Ecol. Appl. 19, 631-642. https://doi.org/10.1890/07-2107.1.

Kaminski, K.J., Islam, K., 2013. Effects of forest treatments on abundance and spatial characteristics of Cerulean Warbler territories. Am. Midl. Nat. 170, 111-120.

Kelty, M.J., D'Amato, A.W., 2005. In: Proceedings of the conference on diameter-limit cutting in northeastern forests. 2005 May 23-24; Amherst, MA. Gen. Tech. Rep. NE341. U.S. Forest Service, Northeastern Research Station, Newtown Square, PA. https://doi.org/10.2737/NE-GTR-342.

Kéry, M., 2018. Identifiability in $N$-mixture models: a large-scale screening test with bird data. Ecology 99, 281-288. https://doi.org/10.1002/ecy.2093.

Kéry, M., Royle, A., 2015. Hierarchical Models for Abundance Workshop. Patuxent Wildlife Research Center. Laurel, MD 9-13 November 2015. Available from < https://www.mbr-pwrc.usgs.gov/workshops/hiermod2015/PatuxNOV_2015/ multinomial Nmixture Bayesian.pdf > (Accessed 22 July 2018).

Kéry, M., Royle, A., 2016. Binomial N-mixture models. In: Applied Hierarchical Modeling in Ecology Analysis of distribution, abundance, and species richness in R and BUGS Vol. 1. Academic Press, London, UK, pp. 219-312.

Linden, D.W., Roloff, G.J., 2013. Retained structures and bird communities in clearcut forests of the Pacific Northwest, USA. For. Ecol. Manage. 310, 1045-1056. https:// doi.org/10.1016/j.foreco.2013.08.059.

Miller, G.W., Kochenderfer, J.N., Fekedulegn, D., 2004. Composition and development of reproduction in two-age Appalachian hardwood stands: 20-year results. USDA Forest Proceedings RMRS-P-34 171-181.

Nareff, G.E., Wood, P.B., Brown, D.J., Fearer, T., Larkin, J.L., Ford, W.M., 2019. Cerulean Warbler (Setophaga cerulea) response to operational silviculture in the central Appalachian region. Mendeley Data, V1. https://doi.org/10.17632/5cvmdfr595.1.

The North American Bird Conservation Initiative in the United States: a Vision of American Bird Conservation (NABCI), 2000. http://nabci-us.org/resources/birdconservation-regions-map/.

Newell, F.L., Rodewald, A.D., 2012. Management for oak regeneration: short-term effects on the bird community and suitability of shelterwood harvests for canopy songbirds. J. Wild. Manage. 76, 683-693. https://doi.org/10.1002/jwmg.314.

Nyland, R.D., 2007. Silviculture: Concepts and Applications. Waveland Press Inc, Long Grove, IL, USA.

Oliarnyk, C.J., Robertson, R.J., 1996. Breeding behavior and reproductive success of Cerulean Warblers in Southeastern Ontario. Wilson Bull. 108, 673-684. https://sora. unm.edu/sites/default/files/journals/wilson/v108n04/p0673-p0684.pdf.

Pagen, R.W., Thompson III, F.R., Burhans, D.E., 2000. Breeding and post-breeding habitat use by forest migrant songbirds in the Missouri Ozarks. Condor 102, 738-747. https://doi.org/10.1650/0010-5422(2000) 102[0738:BAPBHU]2.0.CO;2.

Paton, P.W.C., 1994. The effect of edge on avian nest success: how strong is the evidence? Conserv. Biol. 8, 17-26. https://www.jstor.org/stable/2386717.

Perkey, A.W., Miller, G.W., Feicht, D.L., 2011. Coopers Rock crop tree demonstration area-20-year results. USDA Forest Service Northern Research Station General Technical Report NRS-83. < https://www.nrs.fs.fed.us/pubs/38444 > . 
Perkins, K.A., Wood, P.B., 2014. Selection of forest canopy gaps by male Cerulean Warblers in West Virginia. Wilson J. Ornithol. 126, 288-297. https://doi.org/10. 1676/13-067.1.

Porneluzi, P.A., Brito-Aguilar, R., Clawson, R.L., Faaborg, J., 2014. Long-term dynamics of bird use of clearcuts in post-fledging period. Wilson J. Ornithol. 126, 623-832. https://doi.org/10.1676/14-002.1.

R Core Team, 2018. R: a language and environment for statistical computing. $\mathrm{R}$ Foundation for Statistical Computing, Vienna, Austria. https://www.R-project.org/.

Raybuck, D.W., 2016. Migration and the Post-Fledging Period: Examining Two Critical Stages of the Cerulean Warbler Life Cycle. Master's Thesis. Arkansas State University, Jonesboro, Arkansas.

Robbins, C.S., Fitzpatrick, J.W., Hamel, P.B., 1992. A warbler in trouble: Dendroica cerulea. In: Hagan, J.M., Johnston, D.W. (Eds.), Ecology and Conservation of Neotropical Migrant Landbirds. Smithsonian Institution Press, Washington, D.C, pp. 549-562.

Robbins, M.B., Nyari, A.S., Papes, M., Benz, B.W., 2009. Song rates, mating status, and territory size of Cerulean Warblers in Missouri Ozark riparian forest. Wilson J. Ornithol. 121, 283-289. https://doi.org/10.1676/08-100.1.

Rosenberg, K.V., Kennedy, J.A., Dettmers, R., Ford, R.P., Reynolds, D., Alexander, J.D., Beardmore, C.J., Blancher, P.J., Bogart, R.E., Butcher, G.S., Camfield, A.F., Couturier, A., Demarest, D.W., Easton, W.E., Giocomo, J.J., Keller, R.H., Mini, A.E., Panjabi, A.O., Pashley, D.N., Rich, T.D., Ruth, J.M., Stabins, H., Stanton, J., Will, T., 2016. Partners in flight landbird conservation plan: 2016 Revision for Canada and Continental United States. Partners in Flight Sci. Committee. https://www. partnersinflight.org/resources/the-plan/.

Roth, K.L., Islam, K., 2008. Habitat selection and reproductive success of Cerulean Warblers in Indiana. Wilson J. Ornithol. 120, 105-110. https://doi.org/10.1676/06181.1.

Royle, J.A., 2004. $N$-mixture models for estimating population size from spatially replicated counts. Biometrics 60, 108-115. https://doi.org/10.1111/j.0006-341X. 2004.00142.x.

Ruhl, P.J., Delancey, C.D., Dunning Jr., J.B., 2018. Roost preference, postfledging habitat use, and breeding phenology of adult female Worm-eating Warblers (Helmitheros vermivorum) on the breeding grounds. Wilson J. Ornithol. 130, 397-409. https://doi. org/10.1676/16-222.1.

Sauer, J.R., Niven, D.K., Hines, J.E., Ziolkowski Jr., D.J., Pardieck, K.L., Fallon, J.E., Link, W.A., 2017. The North American Breeding Bird Survey, results and analysis 1966-2015. Version 12.23.2015. USGS Patuxent Wildlife Research Center, Laurel, Maryland, USA. https://www.mbr-pwrc.usgs.gov/bbs/.

Sheehan, J., Wood, P.B., Buehler, D.A., Keyser, P.D., Larkin, J.L., Rodewald, A.D., Wigley, T.B., Boves, T.J., George, G.A., Bakermans, M.H., Beachy, T.A., Evans, A., McDermott, M.E., Newell, F.L., Perkins, K.A., White, M., 2013. Avian response to timber harvesting applied experimentally to manage Cerulean Warbler breeding populations. For. Ecol. Manage. 321, 5-18. https://doi.org/10.1016/j.foreco.2013.
07.037 .

Silvis, A., Perry, R.W., Ford, W.M., 2016. Relationships of three species of white-nose syndrome-impacted bats to forest condition and management. U.S. Forest Service Southern Research Station General Technical Report. SRS-214, Ashville, NC, USA, pp. 57. < https://www.fs.usda.gov/treesearch/pubs/52250 > .

Thogmartin, W.E., 2001. Home-range size and habitat selection of female Wild Turkeys (Meleagris gallopavo) in Arkansas. Am. Midl. Nat. 145, 247-260. https://www.jstor. org/stable/3083104.

Thompson, J.R., Carpenter, D.N., Cogbill, C.V., Foster, D.R., 2013. Four centuries of change in Northeastern United States forests. PLoS ONE 8, e72540. https://doi.org/ 10.1371/journal.pone.0072540.

Tirpak, J.M., Giuliano, W.M., Allen, T.J., Bittner, S., Edwards, J.W., Friedhof, S., Harper, C.A., Igo, W.K., Stauffer, D.F., Norman, G.W., 2010. Ruffed Grouse-habitat preference in the central and southern Appalachians. For. Ecol. Manage. 260, 1525-1538.

USDA Forest Service, 1994. Ecological Subregions of the United States. Compiled by Eastern Region and Northeastern Area State and Private Forestry. Available from < https://www.fs.fed.us/land/pubs/ecoregions/ > (Accessed June 2018).

United States Geological Survey (USGS), 2017. The National Map. Available from < https://nationalmap.gov/elevation.html > (Accessed June 2018).

United States Geological Survey (USGS), 2018. North American Breeding Bird Survey. Available from < https://www.pwrc.usgs.gov/bbs/about/ > . (Accessed June 2018).

Vitz, A.C., Rodewald, A.D., 2006. Can regenerating clearcuts benefit mature-forest songbirds? An examination of post-breeding ecology. Biol. Conserv. 127, 477-486. https://doi.org/10.1016/j.biocon.2005.09.011.

Weakland, C.A., Wood, P.B., 2005. Cerulean warbler (Dendroica cerulea) microhabitat and landscape-level habitat characteristics in Southern West Virginia. Auk 122, 497-508. https://doi.org/10.1642/0004-8038(2005) 122[0497:CWDCMA]2.0.CO;2.

West Virginia Division of Forestry (WVDOF), 2006. Coopers Rock State Forest Forest Resources Management Plan. Available from < http://www.wvforestry.com/CRSF \%20final\%20draft\%201-19-06.pdf > . (Accessed October 2013).

Wood, P.B., Perkins, K.A., 2012. Behavioral activities of male cerulean warblers in relation to habitat characteristics. Wilson J. Ornithol. 124, 497-505. https://doi.org/10. 1676/11-147.1.

Wood, P.B., Bosworth, S.B., Dettmers, R., 2006. Cerulean Warbler abundance and occurrence relative to large-scale edge and habitat characteristics. Condor 108, 154-165. https://doi.org/10.1650/0010-5422(2006) 108[0154:CWAAOR]2.0.CO;2.

Wood, P.B., Sheehan, J., Keyser, P., Buehler, D., Larkin, J., Rodewald, A., Stoleson, S., Wigley, T.B., Mizel, J., Boves, T., George, G., Bakermans, M., Beachy, T., Evans, A., McDermott, M., Newell, F., Perkins, K., White, M., 2013. Management guidelines for enhancing Cerulean Warbler breeding habitat in Appalachian hardwood forests. American Bird Conservancy. The Plains, Virginia, pp. 28. < http://amjv.org/wpcontent/uploads/2018/06/cerulean_guide_1-pg_layout.pdf > . 